\title{
Response Mechanisms of Plants Under Saline-Alkali Stress
}

\author{
Shumei Fang ${ }^{1 *}$, Xue Hou ${ }^{1}$ and Xilong Liang ${ }^{2,3 *}$ \\ ${ }^{1}$ Department of Biotechnology, College of Life Science and Biotechnology, Heilongjiang Bayi Agricultural University, Daqing, \\ China, ${ }^{2}$ Department of Environmental Science, College of Agriculture, Heilongjiang Bayi Agricultural University, Daqing, \\ China, ${ }^{3}$ Heilongjiang Plant Growth Regulator Engineering Technology Research Center, Daqing, China
}

\section{OPEN ACCESS}

Edited by:

Jayakumar Bose,

The University of Adelaide, Australia

Reviewed by:

Parvaiz Ahmad,

Sri Pratap College Srinagar, India

Charu Lata,

National Institute of Science Communication and Information

Resources (CSIR), India

*Correspondence:

Shumei Fang

fangshumei520@126.com

Xilong Liang

xilongliang@126.com

Specialty section:

This article was submitted to

Plant Abiotic Stress,

a section of the journal

Frontiers in Plant Science

Received: 13 February 2021

Accepted: 10 May 2021

Published: 04 June 2021

Citation:

Fang S, Hou X and Liang X (2021) Response Mechanisms of Plants

Under Saline-Alkali Stress.

Front. Plant Sci. 12:667458.

doi: 10.3389/fp/s.2021.667458
As two coexisting abiotic stresses, salt stress and alkali stress have severely restricted the development of global agriculture. Clarifying the plant resistance mechanism and determining how to improve plant tolerance to salt stress and alkali stress have been popular research topics. At present, most related studies have focused mainly on salt stress, and salt-alkali mixed stress studies are relatively scarce. However, in nature, high concentrations of salt and high $\mathrm{pH}$ often occur simultaneously, and their synergistic effects can be more harmful to plant growth and development than the effects of either stress alone. Therefore, it is of great practical importance for the sustainable development of agriculture to study plant resistance mechanisms under saline-alkali mixed stress, screen new saline-alkali stress tolerance genes, and explore new plant salt-alkali tolerance strategies. Herein, we summarized how plants actively respond to saline-alkali stress through morphological adaptation, physiological adaptation and molecular regulation.

Keywords: morphological adaptation, endogenous hormone response, signal transduction, epigenetic regulation, osmotic regulation, saline-alkali stress

\section{INTRODUCTION}

With the increase in population and the deterioration of natural environments, soil salinealkalization has become an increasingly serious global problem (Shabala, 2013). According to statistics, approximately $7 \%$ of the world's land (more than 900 million hectares) is threatened by saline-alkalization, and there are no effective measures by which to control its spread (Li et al., 2014). In China, the area of saline-alkali soil has reached 100 million hectares, and the Songnen Plain in northeastern China accounts for 3.73 million hectares and is one of three typical salinealkali soil distribution areas in the world (the other two are Victoria in Australia and California in the United States) (Feng et al., 2007; Wang et al., 2009). Therefore, soil saline-alkalization is an extensive abiotic stressor and has become a major limiting factor for crop production in global agriculture (Wang H. et al., 2018).

The stress effects of soil saline-alkalization on plants include the effects of both salt stress and alkali stress. According to the salt content and $\mathrm{pH}$ value, the degree of salt-alkali conditions is classified as mild (the salt content is less than $3 \%$, and the $\mathrm{pH}$ is 7.1-8.5), moderate (the salt content is 3-6\%, and the $\mathrm{pH}$ is $8.5-9.5$ ), or severe (the salt content exceeds $6 \%$, and the $\mathrm{pH}$ value exceeds 9.5) (Oster et al., 1999). Salt stress results mainly from $\mathrm{NaCl}, \mathrm{Na}_{2} \mathrm{SO}_{4}$ and other neutral salts. On the one hand, these sodium ions will enter the cell directly through channel and carrier proteins that causes ion toxicity. On the other hand, the high ion concentration outside the cell will reduce the osmotic potential, which drives water molecules out of the cell, leading to physiological drought, that is, osmotic stress. Both of these aspects can cause plant 
metabolic disorders (Richards, 1947). Alkali stress is induced by $\mathrm{NaHCO}_{3}$ and $\mathrm{Na}_{2} \mathrm{CO}_{3}$, which further increase the $\mathrm{pH}$ on the basis of salt stress. Therefore, in addition to ionic toxicity and osmotic stress, high $\mathrm{pH}$ will severely disturb cell $\mathrm{pH}$ stability, destroy cell membrane integrity, and decrease root vitality and photosynthetic function (Zhang et al., 2017; Kaiwen et al., 2020). Many studies have shown that combined salt-alkali stresses result in more serious trophic ion imbalance, reduced osmotic adjustment capacity, inhibition of the antioxidant system, and more serious plant growth inhibition (Amirinejad et al., 2017; Chen et al., 2017; Wang X.-S. et al., 2017; Wang J. et al., 2020). For example, under mild alkali stress, bermudagrass slows metabolic processes such as carbohydrate degradation and $\mathrm{N}$ metabolism to maintain basic growth but with a slower growth rate. Moderately and severely alkali-stressed plants will accumulate relatively higher amounts of carbohydrates and significantly increase ROS and MDA contents (Ye et al., 2021). In short, the osmotic stress, oxidative stress, ionic toxicity and high-pH stress caused by mixed salt-alkali stress can destroy the cell membrane structure, inactivate enzyme activity, disrupt the ion balance in plant cells etc. However, most studies have focused mainly on salt stress, and little attention has been given to salt-alkali mixed stress.

Based on the extent and severity of plant damage due to soil salinization and alkalization, studying and summarizing the response mechanisms of plants under salt-alkali stress is very important. The results will contribute to the breeding of resistant varieties and provide an important theoretical basis for the rational utilization of saline-alkali land and the sustainable development of agriculture. Hence, in this work, we review how plants actively respond to salt-alkali stress on the basis of three different aspects: (1) morphological adaptations; (2) physiological adaptations, including osmotic regulation, ion and $\mathrm{pH}$ balance, antioxidant effects, and endogenous hormone responses; and (3) molecular regulation, including signal transduction, transcription factor involvement, salinealkali resistance gene expression, and epigenetic regulation.

\section{MORPHOLOGICAL ADAPTATIONS TO SALT-ALKALI STRESS}

Under salt-alkali stress, the normal growth, development, and physiological and biochemical metabolism of plants are severely disrupted. When plants are exposed to saline-alkali stress, the roots are the first to perceive the stress information, which is gradually transmitted to the aboveground parts. The root surface area and the root tip number, as well as the leaf area and photosynthetic rate, mainly account for the response of the plant seedling biomass to salt-alkaline stress (An et al., 2021). After long-term exposure to saline-alkali stress, plants can alter their morphology to better adapt to the environment. According to reports, the typical changes in the morphology or anatomy of halophytes in response to salinity mainly include an increase in succulence, leaf pubescence, alterations to the number and size of stomata, a multilayered epidermis, thickening of the cuticle, early lignification, inhibition of differentiation, changes in the xylem vessel diameter and quantity, etc. (Waisel, 1972). Studies on three plant species with different responses to salt stress (Phaseolus vulgaris, which is salt-sensitive; Gossypium hirsutum, which is moderately salt tolerant; and Atriplex patula, which is salt tolerant) have shown that high $\mathrm{Na}^{+}$concentrations significantly reduce the leaf area/plant height ratio. The anatomical structure of the leaves indicated that compared with the other species, the salt-tolerant species $A$. patula had greater leaf thickness due to the increase in the epidermal and mesophyll thickness and increased succulence (Longstreth and Nobel, 1979). Moreover, salt stress led to a decrease in the photosynthetic rate and $\mathrm{CO}_{2}$ concentrations in the chloroplasts, as determined by the stomatal and mesophyll conductance (Wang X. et al., 2018). Furthermore, the anatomical structure of Populus euphratica under salt stress revealed inhibition of xylem differentiation and developmental changes in normal-sized vessels, which improved the plant tolerance to salinity (Chen and Polle, 2010). In addition, studies on cotton and Leymus chinensis have also shown that plants can adapt to salt-alkali stress by increasing their root/shoot ratio and specific root length (Liu B. et al., 2015; Wang Q. H. et al., 2018). Dissections of the root structure showed that stress promoted the maturation of both the hypodermis and endodermis, which formed a well-developed Casparian strip closer to the root apex that is helpful for adaptation (Walker et al., 1984). Moreover, a study on the halophyte plant Kochia sieversiana showed that the cotyledon node zone may play a role in salt and alkali tolerance. Xylem sap collected from the above cotyledon node zone contains less $\mathrm{Na}^{+}$and $\mathrm{Cl}^{-}$under both salt and/or alkali stresses. The selective restriction of ion transport conferred by the cotyledon node zone under both salt and alkali stresses may represent a novel mechanism of salt and alkali resistance in halophyte plants (Wang et al., 2019). At the cell level, cell expansion increases along the radial axis in the epidermis and cortex under high salinity, which is controlled by modifying the cell wall structure. Studies have shown that a proper cell wall structure is important for the cell shape, elasticity, cell expansion direction and overall growth in roots, which can be directly regulated by salt stress (Shoji et al., 2006; Duan et al., 2015). However, the latest report showed that in response to stress, root aquaporin activity, rather than changes in the root xylem structure, controlled hydraulic conductance, which provides new mechanistic and functional insights into plant adaptation to stress (Domec et al., 2021). In summary, salt-tolerant plants exhibit increased resistance by altering both aboveground and belowground organs to construct an appropriate morphological structure to adapt to adversity.

\section{PHYSIOLOGICAL ADAPTATION MECHANISM OF PLANTS UNDER SALINE-ALKALI STRESS}

\section{Increasing Osmotic Regulatory Ability via Accumulation of Small-Molecule Organic Compounds}

Under saline-alkali stress, sodium ion accumulation in the soil causes the osmotic pressure of the soil to be higher than that 
of plant cells. Under these environmental conditions, water exits plant cells, which causes osmotic stress and physiological drought. To cope with this adversity, plant cells synthesize and accumulate several small-molecule organic compounds, such as proline, soluble proteins, betaine, sugar, polyols and polyamines, to maintain intracellular water potential (Sun et al., 2019). These substances exert osmoregulatory ability by altering the solvent properties of water, stabilizing the internal osmotic potential, increasing the thermodynamic stability of folding proteins and protecting the macromolecular structure. Sorghum seedlings reportedly adapt to salt-alkali environments by altering the synthesis of small-molecule compounds such as proline and soluble proteins (Sun et al., 2019). In wheat, salt-alkali stress led to increases in proline, soluble sugar and polyol (sorbitol) contents to counteract the adverse salt-alkaline conditions (Lin et al., 2012; Guo et al., 2015). Exogenous application of salicylic acid and nitric oxide has been reported to increase plant salt tolerance by enhancing the synthesis of proline, glycine betaine, and sugars that contribute to the maintenance of the tissue water content in Vigna angularis (Ahanger et al., 2019). Taken together, these results show that different plant species and different varieties of the same species can respond to salt-alkali stress through changes in different osmotic adjustment substances.

\section{Maintaining $\mathrm{Na}^{+}-\mathrm{K}^{+}$Ion Balance via Channel Proteins and Transporters}

The high concentration of sodium ions in the soil under saline-alkali stress can disrupt the dynamic balance of ions in cells, leading to a series of damaging effects on plants, such as destruction of the cell membrane structure, abnormal metabolons in cells and ionic toxicity (Hasegawa, 2013). Plants alleviate the toxicity of sodium ions mainly through excreting sodium ions from cells and sequestering them through ion antiporters such as NHX7 (also named SOS1) within cell membrane and NHX1 within vacuolar membrane, both of whose activity is regulated by calcium-dependent SOS2/SOS3 kinase complexes (Figure 1) (Bahmani et al., 2015). $\mathrm{Na}^{+}$ transport is driven by proton-driven forces produced by $\mathrm{H}^{+}$ATPase (located within the cell and vacuolar membranes) and $\mathrm{H}^{+}$-VPPase (located within the vacuolar membranes). Saline-alkali stress can increase the activities of $\mathrm{H}^{+}$-ATPase and $\mathrm{H}^{+}$-VPPase. More $\mathrm{H}^{+}$is pumped into the apoplast and vacuole, which increases the transmembrane electrochemical gradient, and enhances the power of $\mathrm{Na}^{+}$flow from the cytoplasm into the apoplast and vacuole (Deinlein et al., 2014; Ye et al., 2019). Moreover, the SOS2-SOS3 complex is sensitive to $\mathrm{Ca}^{2+}$ concentrations, so appropriate $\mathrm{Ca}^{2+}$ levels are beneficial to maintaining sodium ion homeostasis under salinealkali stress.

The potassium $\left(\mathrm{K}^{+}\right)$concentration is closely related to the regulation of osmosis, the membrane potential, and enzyme activity in plants (Hasanuzzaman et al., 2018). A high cytosolic $\mathrm{K}^{+} / \mathrm{Na}^{+}$ratio in the cytoplasm is necessary for normal plant growth and development. Under saline-alkali-stress conditions, a large influx of $\mathrm{Na}^{+}$into the cytoplasm can causes the membrane potential to drop below the resting potential, which then activates the $\mathrm{K}^{+}$outflow channel (such as NSCC, GORK, and SKOR) and disrupts the steady-state equilibrium of the $\mathrm{K}^{+} / \mathrm{Na}^{+}$ratio (Falhof et al., 2016) (Figure 1). There is increasing evidence that some $\mathrm{K}^{+}$channel proteins, including highaffinity $\mathrm{K}^{+}$transporters (HKTs), high-affinity $\mathrm{K}^{+}$absorption transporters channel proteins (HAKs), and Arabidopsis $\mathrm{K}^{+}$ transporters (AKT1), are involved in the $\mathrm{K}^{+}$absorption in plants. HKTs are a kind of transport protein specific for $\mathrm{Na}^{+} / \mathrm{K}^{+}$ (type II). Type II HKTs are selective for $\mathrm{K}^{+}$but can also transport $\mathrm{Na}^{+}$under certain conditions (Cotsaftis et al., 2012). Generally, $\mathrm{K}^{+}$absorption is mediated by members of the $\mathrm{K}^{+}$ transporter HAK/KUP/KT family (such as HAK5 and KUP7) or members of the shaker family of $\mathrm{K}^{+}$channels (such as AKT1) (Li et al., 2018). A recent study showed that many members of the HAK/KUP/KT family are involved in $\mathrm{K}^{+}$ uptake and stress responses in tea plants (Yang T. et al., 2020). Plants overexpressing the HAK gene are highly tolerant to salt under low- $\mathrm{K}^{+}$conditions in cytoplasm. However, under the combined conditions of $\mathrm{Na}^{+}$and low $\mathrm{K}^{+}$in plant cytoplasm, HAK expression is inhibited, the activity of the transporter decreases sharply, and plants become very sensitive. The main reason is that $\mathrm{Na}^{+}$depolarizes the plasma membrane (PM), such that its polarity value is higher than that of the $\mathrm{K}^{+}$ equilibrium potential, thereby activating the outward-rectifying $\mathrm{K}^{+}$channel (such as SKORs) and leading to $\mathrm{K}^{+}$outflow (Pottosin and Dobrovinskaya, 2014; Bacha et al., 2015). In addition, the activity of $\mathrm{PM} \mathrm{H}^{+}$-ATPase is another factor that restricts $\mathrm{K}^{+}$absorption. This protein complex is necessary for protons to be actively pumped out of the cell through an ATP-dependent phosphorylation process, generating a proton motif force (pmf) across the PM (Falhof et al., 2016). HAKs then use the pmf produced by $\mathrm{H}^{+}$-ATPase for $\mathrm{K}^{+}$absorption because HAKs are usually $\mathrm{K}^{+} / \mathrm{H}^{+}$symporters (Bose et al., 2013; Pottosin and Dobrovinskaya, 2014). Thus, limiting membrane depolarization (restricting $\mathrm{Na}^{+}$influx or promoting $\mathrm{Na}^{+}$efflux) and enhancing $\mathrm{H}^{+}$-ATPase activity can increase $\mathrm{K}^{+}$absorption via HAKs under salt stress and increase the resistance to low $\mathrm{K}^{+}$under salt stress. Studies in tomato have indicated that inducing LeHAK5 and supplementing $\mathrm{Ca}^{2+}$ during the $\mathrm{K}^{+}$starvation period can counteract the PM depolarization induced by salt stress by inhibiting NSCCs, thereby increasing the absorption of $\mathrm{K}^{+}$(Bacha et al., 2015). From this point of view, maintaining a high $\mathrm{K}^{+} / \mathrm{Na}^{+}$ratio is an important salt stress adaptation measure. AKT1 participates in high-affinity $\mathrm{K}^{+}$absorption to ensure a constant $\mathrm{K}^{+}$supply, resulting in a high internal- $\mathrm{K}^{+}$to external- $\mathrm{K}^{+}$concentration (Gierth and Mäser, 2007; Demidchik, 2014). When salt stress inhibits the plant's ability to absorb $\mathrm{K}^{+}$from the soil, increasing the external $\mathrm{K}^{+}$concentration helps alleviate salt stress (Rodrigues et al., 2013). In Puccinellia tenuiflora, PutAKT1 has been characterized as encoding a $\mathrm{K}^{+}$transporter/channel expressed under salinealkali-stress conditions (Zhao et al., 2016). The overexpression of PutAKT1 in Arabidopsis seedlings increases $\mathrm{K}^{+}$uptake by cells and reduces $\mathrm{Na}^{+}$accumulation, which proves the role of PutAKT1 (Ardie et al., 2010). As mentioned above, there are many proteins involved in maintaining high cytoplasmic 


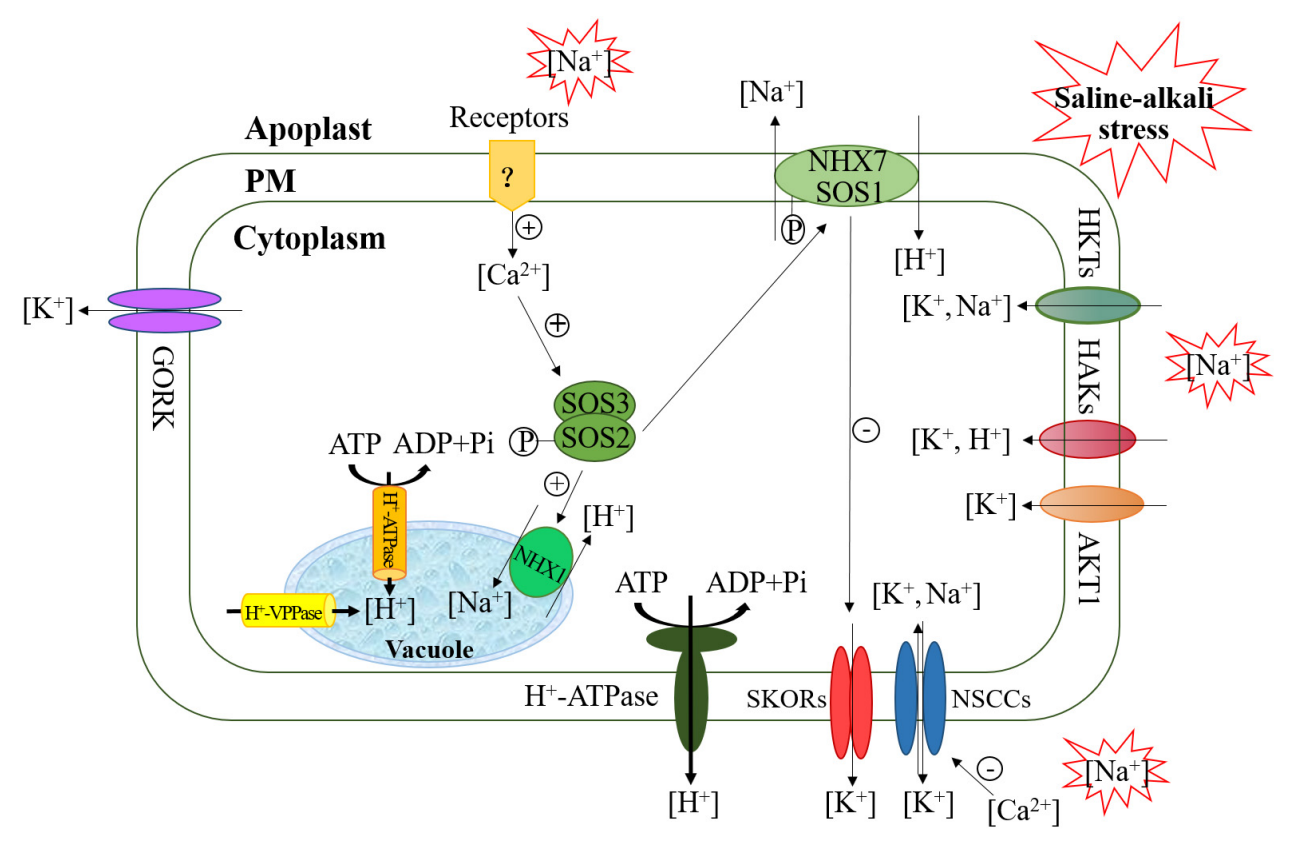

FIGURE 1 | Maintaining $\mathrm{Na}^{+}-\mathrm{K}^{+}$ion balance via channel proteins and transporters.

$\mathrm{K}^{+} / \mathrm{Na}^{+}$ratios and that are prerequisites for salt stress tolerance because a high cytoplasmic $\mathrm{K}^{+} / \mathrm{Na}^{+}$ratio can ensure the best cell metabolic function. In addition, some chemicals regulate tolerance to salinity and alkalinity stress by acting on these protein enzymes or channels. $\gamma$-aminobutyric acid (GABA) accumulation in Arabidopsis corresponded to increased activity of $\mathrm{PM} \mathrm{H}^{+}$ATPase, reduced ROS-induced $\mathrm{K}^{+}$efflux from roots, and lower $\mathrm{Na}^{+}$uptake, which confer salt tolerance to plants (Su et al., 2019). Xu et al. (2019) also reported that GABA can reduce the $\mathrm{Na}^{+} / \mathrm{K}^{+}$ratio by inducing polyamine generation to enhance salinity-alkalinity stress tolerance in muskmelon. Polyamines were reported to assist in the movement and sequestration of $\mathrm{Na}^{+}$from the cytoplasm to the vacuole and affect $\mathrm{K}^{+}$flux by amending outward- and inward-rectifying $\mathrm{K}^{+}$channels in guard cells and root cells (Pál et al., 2015; Pottosin et al., 2020). Moreover, the application of plant growth-promoting rhizobacteria showed an enhanced capacity to counteract salinealkaline stress in Chrysanthemum plants, which can modify cellular abscisic acid levels, inhibit net $\mathrm{K}^{+}$efflux and concurrently induce net $\mathrm{Na}^{+}$efflux by modulating several $\mathrm{Na}^{+} / \mathrm{H}^{+}$and $\mathrm{K}^{+}$ antiporters/channels (Zhou et al., 2017).

\section{Maintaining Intracellular pH Stability Through Secreting and Synthesizing Organic Acids}

High $\mathrm{pH}$ levels in soils occur with increasing saline-alkali stress, which mainly affects the plant root system by destroying root tissue and reducing the root surface area, resulting in root cells losing their normal physiological function (Munns and Tester, 2008; Robin et al., 2016). High-pH stress also causes the mineralization of organic matter such as carbon, nitrogen, phosphorus, and sulfur, which decreases nutrient recycling and availability for plants (Neina, 2019). Studies have shown that many plants can be induced to secrete large amounts of organic acids under saline-alkali stress, which can play a buffering role allowing plants to resist environmental changes and maintain intracellular $\mathrm{pH}$ stability and ion balance (Yang et al., 2010; He et al., 2011; Guo-Hui, 2012). Transcriptomic profiling in grapevine roots revealed that the underlying mechanism of the $\mathrm{NaHCO}_{3}$-induced synthesis of organic acids may be that phosphoenolpyruvate carboxylase catalyzes the carboxylation of phosphoenolpyruvate with $-\mathrm{HCO}_{3}$ to oxaloacetate, which is then converted into oxalate, acetate and malate. The activity of phosphoenolpyruvate carboxylase was regulated by phosphoenolpyruvate carboxylase kinases, which were substantially upregulated by $\mathrm{NaHCO}_{3}$ stress (Xiang et al., 2019). A relative study also showed that proton pump $\mathrm{H}^{+}$ATPase may play an important role in organic acid secretion from roots under $\mathrm{NaHCO}_{3}$ stress (Guo et al., 2018). A study on tomato indicated that both the roots and leaves of plants maintained the ion balance by enhancing the synthesis of organic acids such as citrate, formate, lactate, acetate, succinate, malate and oxalate under salt and alkali stress. In particular, under alkali stress, large amounts of citrate, malate and succinate were synthesized to compensate for the deficiency of inorganic anions (Wang et al., 2011). These results verified the important role of organic acids in maintaining the cell $\mathrm{pH}$ and iron balance. In addition, organic acids are important intermediates of carbon metabolism in plant cells and play other roles in controlling the whole-plant cell physiology, including signaling messengers, modulators of transport across biological membranes, protein modification of acetylation or succinylation and nutrient element uptake from the soil, which can enhance the 
resistance of plants to a certain extent (López-Bucio et al., 2001; Drincovich et al., 2016; Yang T.Y. et al., 2020).

\section{Increasing Resistance to Oxidative Damage via Antioxidant Enzymes and Antioxidants}

Osmotic stress and ionic stress caused by saline-alkali stress further lead to the generation and accumulation of reactive oxygen species (ROS), such as hydrogen peroxide $\left(\mathrm{H}_{2} \mathrm{O}_{2}\right)$ and hydroxyl radicals $\left(\mathrm{OH}^{-}\right.$s). Luo et al. (2021) addressed the mechanism of ROS production triggered by salinity. First, $\mathrm{NaCl}$ induces the expression of Abscisic Acid-Insensitive 4 (ABI4), which can enhance RbohD expression but repress VTC2 expression. Then activated RbohD promotes ROS production while VTC2 repression impairs ROS scavenging. Therefore, this ABI4-RbohD/VTC2 regulatory module positively promotes ROS accumulation (Luo et al., 2021). Accumulated ROS will disrupt the normal physiological functions of cells, resulting in metabolic disorders. There is a set of scavenging systems including antioxidant enzymes and antioxidants for reducing the stress of ROS in plants. The main antioxidant enzymes include superoxide dismutase (SOD), catalase (CAT), peroxidase (POD), glutathione peroxidase (GPX), glutathione reductase (GR) and ascorbic acid peroxidase (APX). SOD is the first line of defense of the antioxidant system in plants and can transform accumulated superoxide molecules into oxygen and $\mathrm{H}_{2} \mathrm{O}_{2}$, after which CAT, APX, and POD convert $\mathrm{H}_{2} \mathrm{O}_{2}$ into water and oxygen. In addition, these enzymes work together to scavenge MDA produced from lipid peroxidation to the protect membrane structure. Antioxidants include mainly glutathione (GSH), ascorbic acid (ASA), mannitol, flavonoids, anthocyanins and vitamin E. These compounds are distributed in different parts of cells to regulate the balance of ROS in cells. Based on the functions of antioxidant enzymes and antioxidants, it is possible to alleviate the injury to cells caused by saline-alkali stress through the cooperation of the two.

A study on rice showed that cell membranes were severely damaged by alkali stress and that the contents of MDA and $\mathrm{H}_{2} \mathrm{O}_{2}$ increased significantly, which stimulated the plants' antioxidant defense system. The activities of antioxidant enzymes such as SOD, POD, CAT, and APX significantly increased. After a $98 \%$ solution of natural anthocyanin exogenous antioxidants was applied, impaired phenotypic characteristics such as wilting, chlorophyll damage and cell death were relieved, and the ROS that accumulated were scavenged (Zhang et al., 2017). A highsalt environment further stimulates the plant response to alkali stress. Sun et al. (2019) reported that under relatively low alkali stress, the activities of SOD and CAT in sorghum seedlings essentially did not change, but under a high-salt environment, with an increase in alkalinity, POD activity increased significantly (Sun et al., 2019). Other studies have also shown that plants can reduce oxidative damage by regulating the activity of antioxidants and antioxidant enzymes to better adapt to salt-alkali stress environments. A study on two different sensitive maize varieties (JY417, a highly salt-tolerant cultivar) and (XY335, a saltsensitive cultivar) showed that saline-alkali stress could increase both ASA and GSH contents. High ASA and GSH contents ensured the successful cyclization of ASA-GSH, which plays an important role in maintaining protein stability and the structural integrity of the biomembrane system and prevents membrane lipid peroxidation. By cooperating with APX, GR and other antioxidant enzymes, ASA and GSH constitute a cyclical system that effectively removes free radicals, thereby enhancing the antioxidant ability and maintaining the balance of active oxygen metabolism in cells to further effectively alleviate damage caused by salt-alkali stress (Fu et al., 2017). A Medicago sativa L. MsSiR overexpression enhanced the alkali tolerance of transgenic plants by increasing the GSH content (Sun et al., 2020). Moreover, many studies have shown that the application of exogenous compounds such as, hydrogen sulfide, GABA, 28-homobrassinolide, 24epibrassinolide, melatonin, salicylic acid, kinetin, jasmonic acid and nitric oxide confers salinity and alkalinity tolerance by upregulating the antioxidant system, ascorbate-glutathione cycle, and glyoxalase system in various plants including soybean, Malus hupehensis, muskmelon, Brassica juncea, Pisum sativum, pepper and tomato cultivars (Ahmad et al., 2017, 2018; Ahanger et al., 2018; Kaur et al., 2018; Alam et al., 2019; Jin et al., 2019; Shams et al., 2019; Kaya et al., 2020; Li H. et al., 2020), which indicates the critical role of the antioxidant system in the stress response.

\section{Increasing Endogenous Hormone Synthesis by Regulating the Expression of Related Genes}

Changes in hormones are an important factor that affect normal plant growth and development under saline-alkali stress. Gibberellin (GA), auxin (IAA), abscisic acid (ABA), cytokinin (CK), ethylene (ET), salicylic acid (SA) and jasmonic acid (JA) are indispensable hormones for plant adaptations to stress, and the concentrations of these hormones are regulated by the expression of hormone-related genes (Ciura and Kruk, 2018; Korver et al., 2018; Kumar et al., 2019). For example, the endogenous GA (GA1 and GA4) content was shown to be less inhibited by saline-alkali stress in a resistant rice variety than in a sensitive variety, and the expression level of GA synthesis-related genes was higher in the former. Several key GA biosynthesis and catabolism-related genes, OsGA20ox, OsGA3ox, and OsGA2ox, in rice were found to participate in the response to saline-alkali stress. The expression of OsGA20ox1 in the sensitive variety decreased but was maintained at a relatively constant level in the resistant variety. Compared with that in the sensitive variety, the expression of OsGA20ox3 in the resistant variety was strongly induced in response to saline-alkali stress ( $\mathrm{Li}$ et al., 2019). Therefore, the resistance mechanisms of plants to salt-alkali stress may be related to the biosynthesis and metabolism of GA. As key hormones for plant growth, IAA and $\mathrm{CK}$ accumulate and are widely distributed in root tips to cope with high-pH environments (Xu et al., 2012). The AUX/LAX family of influx carriers and the PIN family of efflux carriers mediate the polar transport of IAA, which is very important for the distribution and accumulation of IAA in plant roots (Blilou et al., 2005; Overvoorde et al., 2010). Under alkaline stress, the expression of the IAA-related genes ARF5, GH3.6, 
SAUR36, and SAUR32 and the CK-related gene IPT5 in the roots of apple rootstocks was significantly induced, and the contents of IAA and CK greatly increased, thereby increasing the alkali resistance of the apple rootstocks (Liu et al., 2019). Another study confirmed that ET can stimulate the expression of AUX1 and IAA biosynthesis-related genes to increase the accumulation of IAA, thereby regulating the inhibition of root elongation affected by alkaline stress (Li et al., 2015). ABA is an important plant hormone for plant growth, development and responses to stress. Studies have shown that in the ABA signaling pathway, the expression of five genes $\left(S a P Y L_{4-1}\right.$, $S a P Y L_{4-2}, S a P Y L_{4-3}, S a P Y L_{4-4}$, and $\left.S a P Y L_{5-1}\right)$ related to ABA receptors in Sophora alopecuroides is downregulated under salt and alkali treatment. These genes regulate stomatal closure by promoting the accumulation of $\mathrm{ABA}$, thereby reducing the inhibitory effect of saline-alkali stress on photosynthesis and allowing plants to better adapt to the stress environment (Guo et al., 2015; Yan et al., 2020). In sorghum plants, the expression levels of SbNCED3, SbPP2C09, SbPP2C23, SbPP2C52, SbPP2C54, SbPP2C58, SbSAPK1, SbSAPK5, and SbSAPK9 were significantly upregulated under saline-alkali stress, indicating that these genes may play an important role in ABA signaling under salt-alkali stress (Ma et al., 2019). These results indicate that an increase in hormone content enhances the salt-alkali resistance of plants. The application of exogenous hormones such as ABA, SA, and JA also alleviated harmful effects of salt and alkali stresses on various plants, which further verified the role of hormones in enhancing plant resistance (Ahanger et al., 2019; Ali et al., 2020; Li X. et al., 2020).

\section{MOLECULAR MECHANISMS OF PLANT RESPONSES TO SALINE-ALKALI STRESS}

\section{Activation of Signal Transduction Pathways}

The signal transduction pathways of saline-alkali stress mainly include the salt overly sensitive (SOS) pathway, protein kinase pathway and ABA pathway. Among them, the SOS pathway is used for signal transduction under ionic stress, while the protein kinase pathway and ABA pathway are involved mainly in osmotic signal transduction (Zhu, 2016).

The SOS pathway is the first salt-alkali stress signal transduction pathway established in plants and is responsible for the efflux of $\mathrm{Na}^{+}$in cells. In this signaling pathway, the EF-hand chiral calcium-binding proteins Salt Overly Sensitive 3 (SOS3) and SOS3-Like Calcium-Binding Protein (SCaBP8)/Calcineurin B-like Protein 10 (CBL10) are essential for the activation of the SOS signaling pathway. These proteins belong to the $\mathrm{CBL} / \mathrm{SCaBP}$ protein family, with an EF-hand structural region that can bind calcium ions. Calcium signals can be generated under the stimulation of salt stress (Zhu, 2016). Salt Overly Sensitive 2 (SOS2) is a Ser/Thr protein kinase that acts as an intermediate hub in the SOS signaling pathway. When plants grow in a saline-alkali environment, SOS3 and SCaBP8 activate
SOS2 after sensing the calcium signal and combine to form a SOS3-SOS2 protein kinase complex. Activated SOS2 interacts with SOS1 in the $\mathrm{PM}$ and then regulates and activates it by phosphorylation, whose $\mathrm{Na}^{+} / \mathrm{H}^{+}$antitransport activity can export $\mathrm{Na}^{+}$accumulated in the cytoplasm to the outside of the cell. A study has proven that SpSOS1 can improve plant salt tolerance by regulating ion homeostasis and protecting the PM against oxidative damage under salt stress (Zhou et al., 2018). Reverse genetics experiments also verified that SOS1 in PM plays a critical role in the salt tolerance of rice by controlling $\mathrm{Na}^{+}$ homeostasis and contributing to the sensing of sodicity stress (El Mahi et al., 2019). In addition, activated SOS2 can also activate the $\mathrm{Na}^{+} / \mathrm{H}^{+}$antiporter $\mathrm{NHX} 1\left(\mathrm{Na}^{+} / \mathrm{H}^{+}\right.$Exchanger 1) located within the vacuolar membrane by phosphorylation so that the accumulated $\mathrm{Na}^{+}$in the cytoplasm is sequestered into the vacuole to maintain ion homeostasis. A study has shown that upregulation of $M d N H X 1$ expression can enhance salt tolerance in apple plants (Zou et al., 2021). Therefore, the SOS signaling pathway is very important for the salt stress response process.

Plants can respond to alkali and salt stress by regulating osmotic stress signaling pathways including mitogen-activated protein kinases (MAPKs), $\mathrm{Ca}^{2+}$-dependent protein kinases (CDPKs) and CBL-interacting protein kinases (CIPKs) (Shah et al., 2021; Zhang et al., 2021). The MAPK cascade includes MAPKKK, MAPKK, and MAPKs, which are responsible mainly for transmitting extracellular signals into cells. Upstream MAPKKK is first activated by phosphorylation, and MAPKK and MAPK are in turn phosphorylated and activated sequentially. Activated MAPK can phosphorylate transcription factors and other signaling molecules to regulate the expression of downstream genes (Colcombet and Hirt, 2008; Lee et al., 2015). As $\mathrm{Ca}^{2+}$ sensors, CDPKs and CIPKs can directly convert upstream $\mathrm{Ca}^{2+}$ signals into downstream phosphorylation signals to initiate further downstream signal transduction. They play an important role in the transcription process and are an important regulatory protein commonly found in plants (Kudla et al., 2018). Typical CDPKs generally have four domains: a variable N-terminal domain (VNTD), Ser/Thr protein kinase domain (PKD), self-inhibitory junction domain (JD) and calmodulin (CaM)-like regulatory domain (CaM-LD). Studies have shown that when plants are stimulated by stresses such as low or high temperatures, high salt and drought, specific $\mathrm{Ca}^{2+}$ signals form in the cells. $\mathrm{Ca}^{2+}$ directly binds to the CaM-like regulatory domain with an EF-hand-shaped structure at the C-terminus. Changes in the conformation of CDPKs expose the kinase active site and activate kinase activity. In addition, the PKD region activates the substrate by binding ATP or GTP and transferring the $\gamma$-phosphate group to the receptor hydroxyl residue, thereby triggering a variety of physiological responses in plants (Kudla et al., 2010; Liese and Romeis, 2013; Yip Delormel and Boudsocq, 2019). According to a report, a tyrosine phosphatase AtPFA-DSP3 can modulate the salt stress response of Arabidopsis by interacting with and dephosphorylating MAPK family members MPK3 and MPK6, suggesting the importance of MAPK moleculars for plant salt tolerance (Xin et al., 2021). GsMAPK4-overexpressing soybean plants and SeMAPKK-overexpressing Arabidopsis 
both showed significantly increased tolerance to salt stress, suggesting their positive regulatory effects on the salinity tolerance of plants (Qiu et al., 2019; Rehman et al., 2020). Studies on CDPK members showed that CPK12 was involved in plant adaptation to salt stress by regulating $\mathrm{Na}^{+}$and $\mathrm{H}_{2} \mathrm{O}_{2}$ homeostasis in Arabidopsis (Zhang H. et al., 2018). CPK11 improves salt tolerance in transgenic Arabidopsis plants by regulating $\mathrm{Na}^{+}$and $\mathrm{K}^{+}$homeostasis and stabilizing photosystem II (Borkiewicz et al., 2020). CDPK2 plays a positive role in the salt stress response in potato by promoting ROS scavenging and chlorophyll stability and inducing stress-responsive genes, conferring tolerance to salinity (Grossi et al., 2021). Multiple CIPK members participate in the salt stress response. In two genotypes of switchgrass cultivars (a salt-alkali tolerant genotype and a sensitive genotype), CIPK expression was upregulated mainly in the salt-tolerant cultivars, but the expression in the salt-alkali-sensitive variety was still very low (Zhang et al., 2021). In soybean, GmPKS4 improves soybean tolerance to salt and salt-alkali stresses. The overexpression of GmPKS4 enhances the scavenging of ROS, osmolyte synthesis, and transcriptional regulation of stress-related genes (Ketehouli et al., 2021). In Brachypodium distachyon, BdCIPK31 positively regulates salt stress in stomatal closure, ion homeostasis, ROS scavenging, osmolyte biosynthesis, and transcriptional regulation of stress-related genes (Luo Q. et al., 2017). NtCIPK9 increases transgenic plant salt tolerance by promoting the expression of genes controlling ion homeostasis (Lu et al., 2020). ZmCIPK42 enhances salt tolerance in maize through interaction with calcineurin B-like protein 1 and 4 (ZmCBL1, ZmCBL4), as well as a proteinase inhibitor (ZmMPI) (Chen et al., 2021). PpCIPK1 modulates plant salt tolerance in Physcomitrella patens by ionic homeostasis, $\mathrm{H}_{2} \mathrm{O}_{2}$ accumulation, regulating photosynthetic activity. Moreover, the overexpression of PPCIPK1 could completely rescue the salt-sensitive phenotype of sos2-1 to wild-type levels in Arabidopsis, suggesting the powerful function of PpCIPK1 (Xiao et al., 2021). Taken together, these results indicate that the MAPK and CDPK cascade signaling pathways may mediate the response of a variety of plants to salt and alkali stress indifferent ways. More extensive research needs to be carried out in the future.

The ABA pathway includes both ABA-dependent and ABAindependent types, which are involved in the regulation of osmosis, ions, and reactive oxygen species under salt stress by regulating the expression of several tolerance genes (Sah et al., 2016; Yu Z. et al., 2020). The ABA-dependent pathway means that gene expression is induced by exogenous or endogenous $\mathrm{ABA}$, and the $\mathrm{ABA}$-independent pathway is a way in which gene expression is not only induced by ABA but also affected by biotic or abiotic stress (Fujii and Zhu, 2009; Cutler et al., 2010; Umezawa et al., 2010). The ABA signaling pathway has four core components: (1) a pyrabactin resistance 1/PYR1-like/ABA receptor regulatory component (PYR1/PYL/RCAR), which is the main receptor of ABA; (2) 2C-type protein phosphatases (PP2Cs), which is negative regulators of ABAs; (3) sucrose non-degradable related protein kinase 2 (SnRK2s), which is a unique Ser/Thr protein kinase; and (4) an ABA-response element (ABRE)-binding protein (AREB)/ABRE-binding factor (ABF)
(Kulik et al., 2011; Nakashima and Yamaguchi-Shinozaki, 2013; Tian et al., 2015; Singh et al., 2016). In the absence of $\mathrm{ABA}$ or under low ABA concentrations, PP2C can interact with dephosphorylated SnRK2 and inhibit SnRK2 activity, thereby inhibiting ABA signaling. When ABA accumulates in plants under adverse stress conditions, the receptor RCAR binds to ABA and competitively binds to PP2Cs to release SnRK2. Activated SnRK2s then activate and phosphorylate the downstream transcription factor $A R E B / A B F$ and initiate the $\mathrm{ABA}$ response to regulate various processes of plant growth and development under adverse stress conditions (Fujita et al., 2013; Nakashima and Yamaguchi-Shinozaki, 2013). Studies have shown that, among the 10 members of SnRK2 family in Arabidopsis, the expression of SnRK2.1-SnRK2.10 except SnRK2.9 can be induced by $\mathrm{NaCl}$ (Kobayashi et al., 2004). Overexpression of PtSnRK2.5 and PtSnRK2.7 in Arabidopsis increased the tolerance of the transgenic plants to salt stress (Song et al., 2016). Moreover, overexpression of a novel gene, AsSnRK2D, in tobacco significantly improved the plant tolerance to dehydration or salinity stress. The molecular mechanism might be attributed to the significantly upregulated transcripts of several environmental stress-inducible genes, including dehydrins, cell signaling components, transcription factors, antioxidative enzymes, and proline biosynthesis (Xiang et al., 2020). In addition, GsSKP21, as a Glycine soja S-phase kinase-associated protein, plays a critical regulatory role in the ABA-mediated stress response. Overexpression of GsSKP21 in Arabidopsis dramatically increased the plant tolerance to alkali stress and mediated ABA signaling by altering the expression levels of the ABA signaling-related and ABA-induced genes (Liu A. et al., 2015).

\section{Induction of Transcription Factor Expression}

During signal transduction in response to salt-alkali stress, transcription factors serve as a bridge between stimulus signals and associated genes. They receive upstream signals and regulate the expression of related downstream resistance genes by binding to their corresponding cis-regulatory sequences. Transcriptome analysis of switchgrass and alfalfa indicated that the expression levels of many transcription factors were significantly modified in response to saline-alkaline stress. They belong to major transcription factor families such as AP2/ERF, NAC, HDzip/bZIP, MYC/MYB, WRKY, and bHLH, many of whose members have been shown to be related to the salt-alkali stress response (An et al., 2016; Wang J. et al., 2020; Shah et al., 2021; Zhang et al., 2021).

The $\mathrm{AP}_{2} / \mathrm{ERF}$ transcription factor family is a large family unique to plants with at least one or two highly conserved DNA-binding domains, which are involved in regulating plant growth, development and responses to abiotic stress (Phukan et al., 2017). GsERF6 significantly enhanced plant tolerance to alkaline stress in transgenic Arabidopsis, probably by inducing plant hormones such as ABA and ET as signaling molecules to activate a number of hormone- and stress-responsive genes, such as $R A B 18, R D 29 A, R D 29 B$, and COR47 genes, and some ERF-like 
genes (Yu et al., 2016). ItERF can improve Arabidopsis thaliana salt tolerance by activating the expression of stress-related genes through binding to the GCC-box (Wu J. et al., 2019). Genomewide analysis in adzuki bean showed that the expression of 13 ERF genes was induced in response to saline-alkaline stress. Overexpression of VaERF3 in transgenic Arabidopsis enhances saline-alkaline tolerance by activating the transcription of stressresponsive genes in an ABA-dependent manner ( $\mathrm{Li} \mathrm{W}$. Y. et al., 2020). GsERF71 enhances the tolerance of transgenic Arabidopsis plants to alkaline stress by upregulating the expression levels of $\mathrm{H}^{+}$-ATPase and by modifying auxin accumulation in transgenic plants (Yu et al., 2017). In rice, OsSTAP1 functions as an AP2/ERF transcriptional activator, and plays a positive role in salt tolerance by decreasing the $\mathrm{Na}^{+} / \mathrm{K}^{+}$ratio and maintaining cellular redox homeostasis (Wang Y. et al., 2020). Other ERF family members such as LkERF-B2, ERF38, MbERF11 are also reported to improve salinity tolerance (Cao et al., 2019; Cheng et al., 2019; Han et al., 2020).

Recent studies have shown that bZIPs participate in bZIP transcriptional activation under bicarbonate-alkali stress and alter stress-related physiological indicators (such as reducing the accumulation of MDA and increasing both the activity of POD and the content of chlorophyll) and gene expression (excess GsbZIP67 expression in alfalfa) to improve salt-alkali tolerance (Wu et al., 2018). Members of the bZIP transcription factor family have been identified in a variety of higher plants. Plant-specific HD-Zip I transcription factor MdHB-7 regulates salt tolerance in transgenic apple (Malus domestica). The overexpression of $\mathrm{MdHB}-7$ reduced the salt stress-induced damage, maintained ion homeostasis, and promoted the detoxification of ROS, while $M d H B-7$ RNAi lines showed the opposite performance (Zhao et al., 2021). Populus nigra PnHB7 transcription factor overexpression in tobacco also improved the resistance of transgenic plants to salt stress. Transcriptome analysis of overexpressed tobacco showed that hormone-related protein genes, oxidase genes and transcription factor protein genes in the ABA signaling pathway were significantly upregulated, suggesting that PnHB7 plays an important role in the ABA regulation pathway (Yu X. et al., 2020). A novel bZIP transcription factor, ChbZIP1, from the alkaliphilic microalgae Chlorella sp. BLD has been reported to increase the alkali resistance of plants. Overexpression of ChbZIP1 in Arabidopsis showed that ChbZIP1 can enhance plant adaptation to alkali stress through the active oxygen detoxification pathway, suggesting its promising potential in genetically improving plant tolerance to alkali stress (Qu et al., 2021). bZIP transcription factors are similar to MYB/MYC transcription factors in terms of their regulation, participation in ABA-dependent pathway signal transduction, and perception of stress signals to regulate gene expression.

Under long-term salt-alkali stress, the members of the MYB transcription factor family exhibited the most significant changes in alfalfa, and the expression of most MYB transcription factors tended to increase (Coskun et al., 2016). In the analysis of alfalfa transcripts, the MYB family was the transcription factor family whose members presented the second strongest response to salt stress after $\mathrm{AP}_{2}$ members, indicating that MYBs play an important role in alfalfa salt-alkali resistance (Postnikova et al., 2013). Transcriptional profiling reveals that the MYB transcription factor MsMYB4 contributes to the salinity stress response of alfalfa. The introduction of MsMYB4 significantly increased salinity tolerance in transgenic Arabidopsis plants in an ABA-dependent manner (Dong et al., 2018). GmMYB68 overexpression enhanced salt-alkali resistance in soybean, whose osmotic adjustment and photosynthetic rates were stronger than those of GmMYB68-RNAi and wildtype plants. Importantly, the overexpression of GmMYB68 also increased the grain number and 100-grain weights under salt stress, indicating the value of its practical application to increase crop yields (He et al., 2020). GmMYB3a, as another MYB transcription factor, showed a negative regulatory effect on soybean response to salt-alkali stress. Overexpression of GmMYB3a reduced physiological parameters, including soluble sugar, free proline, and chlorophyll contents, and photosynthetic rate and downregulated a set of key genes associated with plant defense signal pathways in the transgenic plants (He et al., 2018). TaMYB86B encodes an R2R3-type MYB transcription factor. Overexpression of TaMYB86B can increase the salt resistance of wheat by regulating ion homeostasis to maintain an appropriate osmotic balance and decrease ROS levels (Song et al., 2020b). The R2R3-MYB transcription factor AtMYB49 modulates salt tolerance in Arabidopsis by modulating the cuticle formation and antioxidant defense. Overexpression of AtMYB49 in Arabidopsis increases $\mathrm{Ca}^{2+}$ accumulation in leaves, reduces oxidative damage and improves the membrane integrity through upregulation of the expression of genes encoding PODs and SODs and LEAs and decreases non-stomatal leaf water loss by positively modulating cutin deposition in leaves through upregulation of genes classified into cutin, suberin and wax biosynthesis during salt stress. These actions are probably achieved through ABA-dependent signaling pathways with the involvement of at least ABF3 and ABI5 (Zhang P. et al., 2020).

The WRKY gene family, as a plant-specific transcription factor group, plays important roles in many different response pathways to saline and alkali stresses (Li W. et al., 2020). A large number of WRKYs have been functionally characterized in plants. In sweet potato (Ipomoea batatas L.), 79 IbWRKY transcription factors were identified and 35 IbWRKY genes showed significantly expression changes upon $\mathrm{NaCl}$ treatment (Qin et al., 2020). In the sugar beet genome, a total of 58 putative $B v W R K Y$ genes were identified. $B v W R K Y 10$ in shoots and BvWRKY16 in roots were remarkably upregulated by alkaline stress (Wu G. Q. et al., 2019). In Iris lactea var. chinensis, the expression of IlWRKY1 was notably increased under $\mathrm{NaCl}$ stress, suggesting that IlWRKY1 may be involved in I. lactea var. chinensis sodium salt responses (Tang et al., 2018). Overexpression of SlWRKY28 improved the tolerance of Populus davidiana $\times$ Populus bolleana to saltine-alkaline stress by inducing regulation of the enzyme gene in the ROS scavenging pathway (Wang X. et al., 2020). GmWRKY16 could be induced to express by salt in soybean. GmWRKY16 transgenic Arabidopsis showed improved salt tolerance by activating the expression of AtWRKY8, KIN1, and RD29A in the ABA pathway 
(Ma et al., 2018). In alfalfa, MsWRKY11 was upregulated in response to salinity and alkalinity stresses. Overexpression of the MsWRKY11 gene enhanced salt tolerance in soybean by increasing soluble protein and proline contents and reducing ROS levels, but the detailed regulatory mechanisms remain to be further investigated (Wang Y. et al., 2018). MdWRKY100 overexpression enhanced salt tolerance in $M$. domestica, which was upregulated by the miR156/SPL regulatory module (Ma et al., 2021). MxWRKY64, which is a new WRKY transcription factor gene from Malus xiaojinensis, was induced to express by salt stress in M. xiaojinensis seedlings. Overexpression of MxWRKY64 in transgenic $A$. thaliana contributed to morphological and physiological indicators, suggesting its important role in the response to salt stress (Han et al., 2021). However, not all WRKYs found will improve salt or alkali tolerance. The transcription factor SbWRKY50 from sweet sorghum is negatively involved in the salt response, reducing salt tolerance in $A$. thaliana by directly binding to the upstream promoter of SOS1 and HKT1 to control ion homeostasis (Song et al., 2020a). The maize ZmWRKY114 gene also negatively regulates salt-stress tolerance in transgenic rice by attenuating ABA signaling (Bo et al., 2020).

The plant-specific NAC transcription factor family has received much attention in responses to salinity and alkali stress (Marques et al., 2017; Khan et al., 2018). Plant adaptation to environments with high salinity and alkalinity may be related to the different patterns of action of NAC factors. ThNAC13 was reported to improve salt and osmotic stress tolerance in Transgenic Tamarix and Arabidopsis by enhancing the ROSscavenging capability and adjusting the osmotic potential (Wang L. et al., 2017). Overexpression of GsNAC019 in Arabidopsis resulted in enhanced tolerance to alkaline stress at the seedling and mature stages, but reduced ABA sensitivity, implying that GsNAC019 may contribute to alkaline stress tolerance via the ABA signal transduction pathway and regulate the expression of downstream stress-related genes such as AtRD29B (Cao et al., 2017). Under salt stress, the MdNAC047 gene was significantly induced and MdNAC047 directly activated the expression of MdERF3 by binding to its promoter, facilitating ethylene release, which enhanced the plant tolerance to salt stress (An et al., 2018). Zhang et al. (2015) revealed that wheat TaNAC47 enhanced salt tolerance by interacting with ABRE cis-elements, implying that TaNAC47 may participate in the ABA-dependent signaling pathway. Moreover, PeNAC036 overexpression enhanced Arabidopsis plant salt stress responses, while transgenic plants overexpressing PeNAC034 in Arabidopsis and PeNAC045 in poplar were sensitive to salt (Lu et al., 2018). These results indicate versatile roles of NAC in the responses to salt and alkali stress in plants.

\section{Upregulation of Salt-Alkali Resistance Gene Expression}

Salt-alkali stress induces the expression of related resistance genes, which are involved mainly in osmotic regulation, ion homeostasis, oxidative activity and hormone signal transduction. Studies have shown that in response to high-pH stress, the expression of genes involved in ionic homeostasis and starch and sucrose metabolism is significantly upregulated in cotton. These genes in turn induce plant hormone signal transduction and key enzyme activity to counteract ion toxicity (Zhang B. et al., 2018).

Resistance genes related to osmotic regulation are involved mainly in the synthesis of key enzymes needed for osmotic regulation. Studies have shown that MsGSTU8 in transgenic tobacco increases the soluble sugar content under salt-alkali stress. In addition, the expression of genes related to proline biosynthesis, including NtP5Cs, NtLEA5, and NtLEA14, was upregulated. This shows that the expression of genes involved in the synthesis of osmotic substances increases plant resistance (Du et al., 2019). $\Delta^{1}$-pyrroline-5-carboxylate synthetase (P5CS) is a key enzyme involved in the biosynthesis of proline. Upregulated expression of PutP5Cs unigenes under saltalkali stress significantly increased the content of proline in $P$. tenuiflora, mediating osmotic adaptation to saline-alkaline soil (Ye et al., 2019).

Some saline-alkali resistance genes encoding reverse transport protein/channel ions, including the PutAKT1, PutCAX1, PutNHA1, HKT, and NHX genes, play an important role in the response to ion stress. Studies have shown that PutAKT1 is involved in mediating $\mathrm{K}^{+}$absorption. The expression of PutAKT1 in Arabidopsis increases the $\mathrm{K}^{+}$content and decreases the $\mathrm{Na}^{+}$content in the shoots and roots (Ardie et al., 2010). Under saline-alkali stress, the expression of NHX2 is upregulated in cotton root and leaf tissues (Zhang et al., 2016). OsHKT1;4 and OsHKT1;5 in rice can alleviate the effects of excessive $\mathrm{Na}^{+}$ and reduce ion toxicity (Kobayashi et al., 2017). In addition, salt stress induces the expression of AtHKT1;1 in Arabidopsis, reduces the $\mathrm{Na}^{+}$content in plants and reduces toxicity (An et al., 2017).

Antioxidant-related genes in plants induce the synthesis of key antioxidant enzymes such as SOD, POD, CAT, and GSH, thereby removing active oxygen to protect organisms from oxidative damage. Glutathione $S$-transferase (GST) is a large multifunctional protective cellular enzyme in plants. Members of the GST family quench reactive molecules and catalyze the binding of GSH to hydrophobic and electrophilic substrates, thereby protecting cells from oxidative damage (Liu et al., 2017; Kayum et al., 2018). Overexpression of the MsGSTU8 gene in transgenic tobacco induced the expression of three ROS detoxification-related genes (NtSOD, NtPOD, and NtCAT), which in turn reduced the accumulation of ROS and the content of MDA; increased the activity of SOD, POD, and CAT; and improved the resistance of transgenic tobacco to salt-alkali stress (Du et al., 2019). Based on a large number of studies on the tolerance of plants under salt/alkali stress, a type of plant metallothionein (MT) related to the resistance of plants under extreme environmental stress has been identified. MTs compose a family of low-molecular weight $(7-10 \mathrm{kDa})$ proteins that are rich in Cys and can bind to metals in a variety of organisms. When plants are exposed to metal and/or saline-alkali stress, MT function is triggered in the plants. MTs in plants can be divided into four types according to the distribution of Cys: MT1, MT2, MT3, and MT4 (Cobbett and Goldsbrough, 2002). The cysteine within MTs directly participates in the process of removing ROS, which reduces 
TABLE 1 | List of genes associated with salinity and alkalinity adversity response in plants.

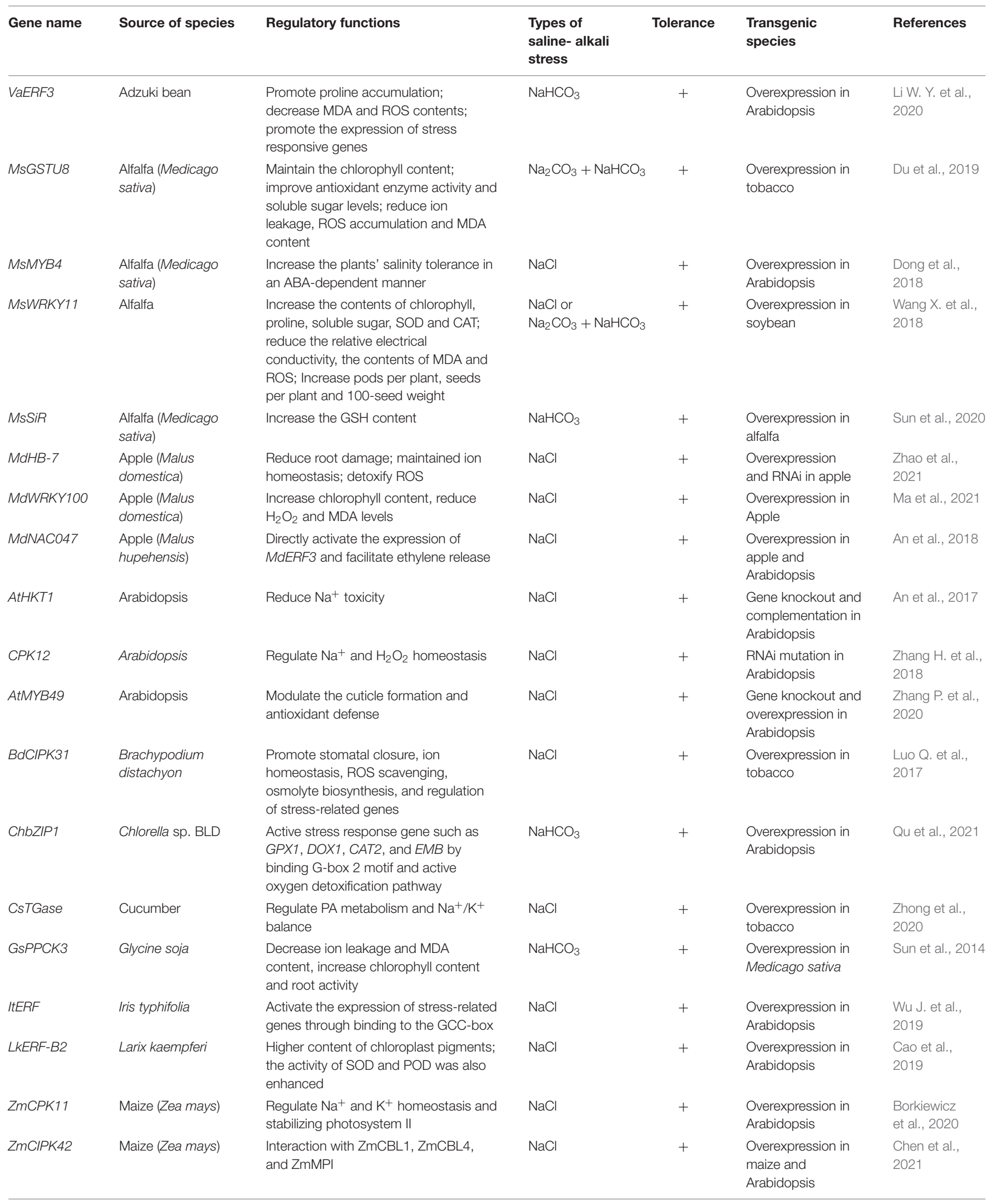


TABLE 1 | Continued

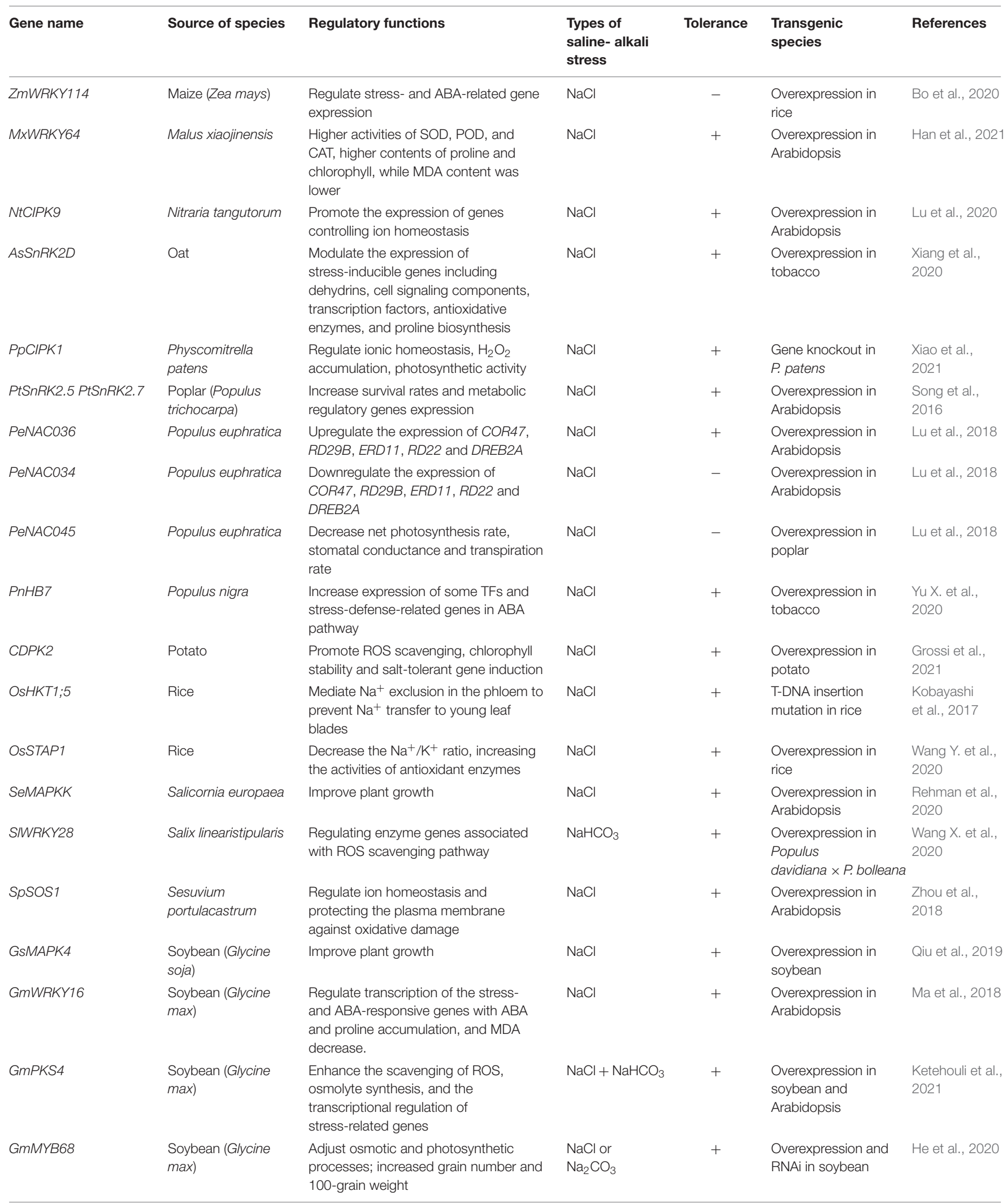


TABLE 1 | Continued

\begin{tabular}{|c|c|c|c|c|c|c|}
\hline Gene name & Source of species & Regulatory functions & $\begin{array}{l}\text { Types of } \\
\text { saline- alkali } \\
\text { stress }\end{array}$ & Tolerance & $\begin{array}{l}\text { Transgenic } \\
\text { species }\end{array}$ & References \\
\hline GmMYBЗа & $\begin{array}{l}\text { Soybean (Glycine } \\
\max \text { ) }\end{array}$ & $\begin{array}{l}\text { Free Pro content decrease; } \\
\text { photosynthesis rate decrease; reduced } \\
\text { the transcription of stress related genes }\end{array}$ & $\begin{array}{l}\mathrm{NaCl} \text { or } \\
\mathrm{Na}_{2} \mathrm{CO}_{3}\end{array}$ & - & $\begin{array}{l}\text { Overexpression in } \\
\text { soybean }\end{array}$ & He et al., 2018 \\
\hline GsSKP21 & $\begin{array}{l}\text { Soybean (Glycine } \\
\text { soja) }\end{array}$ & $\begin{array}{l}\text { Altering the expression of } \mathrm{ABA} \\
\text { signaling-related and } \mathrm{ABA} \text {-induced } \\
\text { genes }\end{array}$ & $\mathrm{NaHCO}_{3}$ & + & $\begin{array}{l}\text { Overexpression in } \\
\text { Arabidopsis }\end{array}$ & $\begin{array}{l}\text { Liu A. et al., } \\
2015\end{array}$ \\
\hline GsERF6 & $\begin{array}{l}\text { Soybean (Glycine } \\
\text { soja) }\end{array}$ & ABA and ET signaling pathways & $\mathrm{NaHCO}_{3}$ & + & $\begin{array}{l}\text { Overexpression in } \\
\text { Arabidopsis }\end{array}$ & Yu et al., 2016 \\
\hline GsERF71 & $\begin{array}{l}\text { Soybean (Glycine } \\
\text { soja) }\end{array}$ & $\begin{array}{l}\text { Upregulate } \mathrm{H}^{+} \text {-ATPase expression and } \\
\text { by modifying auxin accumulation }\end{array}$ & $\mathrm{NaHCO}_{3}$ & + & $\begin{array}{l}\text { Overexpression in } \\
\text { Arabidopsis }\end{array}$ & Yu et al., 2017 \\
\hline GsNAC019 & $\begin{array}{l}\text { Soybean (Glycine } \\
\text { soja) }\end{array}$ & $\begin{array}{l}\text { Regulate expression of } \\
\text { stress-responsive genes, decreases } \\
\text { plant ABA sensitivity, recognize } \\
\text { AtRD29B promoter }\end{array}$ & $\mathrm{NaHCO}_{3}$ & + & $\begin{array}{l}\text { Overexpression in } \\
\text { Arabidopsis }\end{array}$ & $\begin{array}{l}\text { Cao et al., } \\
2017\end{array}$ \\
\hline SsMT2 & Suaeda salsa & $\begin{array}{l}\text { Directly bind ion and trigger other } \\
\text { genes' function, or indirectly improve } \\
\text { ROS scavenging }\end{array}$ & $\begin{array}{l}\mathrm{NaCl} \text { or } \\
\mathrm{NaHCO}_{3}\end{array}$ & + & $\begin{array}{l}\text { Overexpression in } \\
\text { Arabidopsis }\end{array}$ & Jin et al., 2017 \\
\hline SbWRKY50 & Sweet sorghum & $\begin{array}{l}\text { Directly binding to the upstream } \\
\text { promoter of SOS1 and/or HKT1 to } \\
\text { control ion homeostasis }\end{array}$ & $\mathrm{NaCl}$ & - & $\begin{array}{l}\text { Overexpression in } \\
\text { Arabidopsis and } \\
\text { sweet sorghum }\end{array}$ & $\begin{array}{l}\text { Song et al., } \\
2020 a\end{array}$ \\
\hline ThNAC13 & Tamarix hispida & $\begin{array}{l}\text { Enhance the ROS-scavenging } \\
\text { capability and adjusting osmotic } \\
\text { potential }\end{array}$ & $\mathrm{NaCl}$ & + & $\begin{array}{l}\text { Overexpression and } \\
\text { RNAi in T. hispida; } \\
\text { Overexpression in } \\
\text { Arabidopsis }\end{array}$ & $\begin{array}{l}\text { Wang L. et al., } \\
2017\end{array}$ \\
\hline ТамҮВ86B & Wheat & $\begin{array}{l}\text { Regulate ion homeostasis, maintain } \\
\text { osmotic balance and decrease ROS } \\
\text { levels }\end{array}$ & $\mathrm{NaCl}$ & + & $\begin{array}{l}\text { Overexpression in } \\
\text { wheat }\end{array}$ & $\begin{array}{l}\text { Song et al., } \\
\text { 2020b }\end{array}$ \\
\hline TaNAC47 & Wheat & $\begin{array}{l}\text { Up-regulate stress responsive genes in } \\
\text { ABA pathway, including AtRD29A, } \\
\text { AtRD29B, AtCOR47, AtRD20, } \\
\text { AtGSTF6, and AtP5CS1 by binding } \\
\text { ABRE cis-element }\end{array}$ & $\mathrm{NaCl}$ & + & $\begin{array}{l}\text { Overexpression in } \\
\text { Arabidopsis }\end{array}$ & $\begin{array}{l}\text { Zhang et al., } \\
2015\end{array}$ \\
\hline
\end{tabular}

the accumulation of ROS in cells (Nzengue et al., 2012). For example, the $S s M T 2$ gene can improve a plant's $\mathrm{H}_{2} \mathrm{O}_{2}$-scavenging ability and can maintain $\mathrm{H}_{2} \mathrm{O}_{2}$ at low levels in transgenic Arabidopsis, thereby improving tolerance (Jin et al., 2017). This shows that MT2 may have an antioxidant effect by participating in reducing the accumulation of ROS, thereby reducing cell damage, and that MT2 plays no part in metal sequestration. Phosphoenolpyruvate carboxylase (PEPC) is a strictly regulated cytoplasmic enzyme that plays a role in carbon fixation during photosynthesis. The role of PEPC kinase (PPCK) is to control the phosphorylation state and biological activity of PEPC. Studies have shown that PEPC/PPCK plays an important role in responses to environmental stress. One of the best examples is the significant increase in PPCK activity under salt stress (García-Mauriño et al., 2003; Peng et al., 2012; Monreal et al., 2013). Studies of alfalfa plants expressing the GsPPCK3 gene have shown that under alkaline stress, transgenic alfalfa plants present increased resistance (Sun et al., 2014). In addition, transglutaminases (TGases), which are enzymes catalyzing the posttranslational modification of proteins, were induced by salt stress in cucumber. Ectopic overexpression of CsTGase in tobacco showed that CsTGase enhanced salt tolerance by regulating antioxidant activities, the $\mathrm{Na}^{+} / \mathrm{K}^{+}$balance, and PA metabolism in transgenic lines (Zhong et al., 2020). Some genes associated with salinity and alkalinity adversity response in plants are seen in Table 1.

\section{Epigenetic Changes}

Plant tolerance to saline-alkali stress also involves the regulation of epigenetic mechanisms, mainly DNA methylation and histone modification. These heritable changes can influence chromatin structure, which results in gene expression alterations without changes in the underlying DNA sequence (Verhoeven et al., 2010; Zhang et al., 2010; Ganguly et al., 2017; Hewezi, 2018).

In plants, DNA methylation commonly occurs at cytosine sites within $\mathrm{CpG}, \mathrm{CpHpG}$ and $\mathrm{CpHpH}$ sequence contexts (He et al., 2011; Lang et al., 2015). Cytosine methylation is established through de novo methylation and maintenance methylation mediated by RNA-directed DNA methylation (RdDM) pathway and several DNA methyltransferases such as DRM1, DRM2, MET1 and CMT3 (Matzke and Mosher, 2014). Methyl groups on these cytosines can also be removed by either passive DNA demethylation (failure to maintain methylation after replication) or active DNA demethylation mediated by members of the bifunctional DNA glycosidase subfamily including Demeter (DME), Repressor of Silencing 1 (ROS1) and Demeter-like 
(DML) (Gehring et al., 2006; Morales-Ruiz et al., 2006; Zhu, 2009; Lang et al., 2017; Park et al., 2017). By methylation/demethylation processes, DNA methylation in plants can be dynamically regulated and maintained at a proper level. Previous studies have shown that gene expression in plants can be altered through DNA hypomethylation or hypermethylation to adapt to saltalkali-stress environments (Marconi et al., 2013; Viggiano and de Pinto, 2017). In a salt-tolerant Setaria italica L. cultivar, the expression of stress-responsive genes is correlated with DNA demethylation events under salinity stress (Pandey et al., 2017). NtGPDL gene demethylation within the coding sequence of tobacco was shown to be induced by salt stress, which increased NtGDPL gene expression (Choi and Sano, 2007). However, in Medicago truncatula and olive plants, salinity stress increased DNA methylation levels, which regulated the expression of several stress-responsive genes as a stress-adaptive response (Yaish et al., 2018; Mousavi et al., 2019).

Nucleosome core complex histones undergo various posttranslational modifications, including acetylation, phosphorylation, ubiquitination, biotinylation, and sumoylation, which influence chromatin structure and thus determine the expression levels of some genes (Nathan et al., 2006; Camporeale et al., 2007; Sridhar et al., 2007; Luo M. et al., 2017; Su et al., 2017). Therefore, it is understandable that stress-induced gene regulation is associated with histone modifications. Under salt stress, changes in histone modification are involved in the regulation of plant growth and development. Salt stress was shown to increase flowering inhibitor Flowering Locus C (FLC) expression in Arabidopsis by reducing the interaction of the floral initiator Shk1 kinase binding protein 1 (SKB1) with chromatin and by reducing H4R3 symmetric dimethylation (H4R3sme2) levels, thereby regulating flowering time (Zhang et al., 2011). In maize roots, salt stress induces changes in histone acetylation within the promoter regions of cell cycle-related genes (Zhao et al., 2014; Zhou et al., 2014). Elevated acetylation levels at $\mathrm{H} 3 \mathrm{~K} 9$ and $\mathrm{H} 3 \mathrm{~K} 27$ sites lead to transcriptional activation of POX-encoding genes in Beta vulgaris and Beta maritima under salt-stress conditions (Yolcu et al., 2016). The transcription factor MsMYB4 is an important component of the response of alfalfa to salinity stress. The activation of MsMYB4 was reported to be associated with a reduction in the DNA methylation status and an increase in histone $\mathrm{H} 3 \mathrm{~K} 4$ trimethylation and $\mathrm{H} 3 \mathrm{~K} 9$ acetylation in the promoter (Dong et al., 2020).

Many salt-responsive small RNAs have been documented in plants, including miRNAs and siRNAs. Their functions in response to salt stress in plants were reviewed by Kumar et al. (2018). Further small RNA and degradome sequencing of superior stress-tolerant wheat revealed 219 novel and 98 known miRNA sequences. A number of target genes of the miRNAs participating in multiple processes have been identified, among which jasmonate signaling and carbohydrate metabolism are

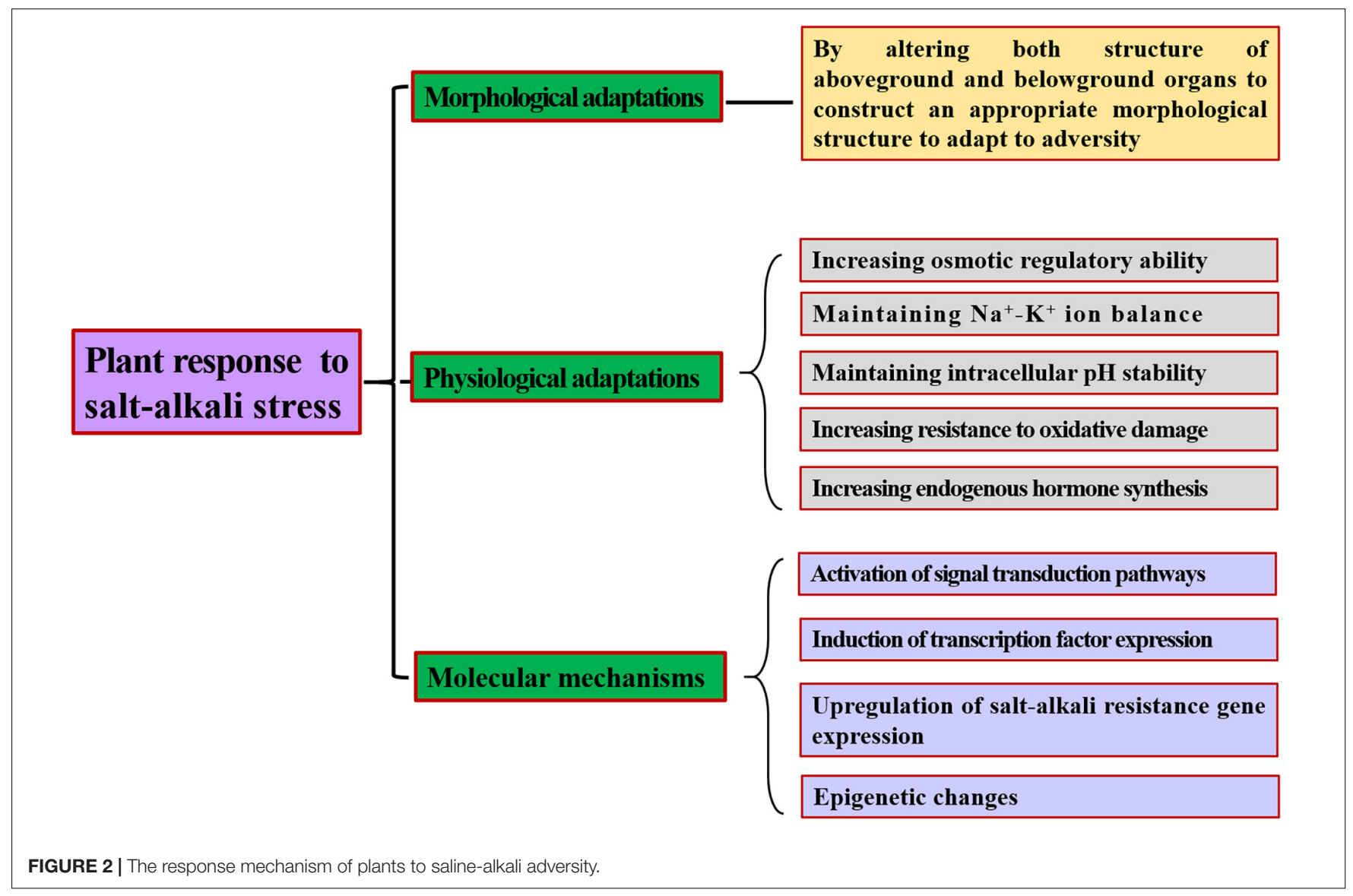


important for salinity tolerance, and proton transport is vital for alkalinity tolerance (Han et al., 2018). In a typical halophyte, Reaumuria soongorica, 13 novel miRNAs were discovered under salt stress. miRNA-mRNA integrated analysis revealed that miRNAs regulate the network response to salt stress during seed germination through GA, auxin, and ABA signaling pathways (Zhang H. et al., 2020). In addition, a comparative transcriptome analysis revealed some new lncRNAs in sweet sorghum, including lncRNA13472, lncRNA11310, lncRNA2846, lncRNA26929, and lncRNA14798. They potentially participate in the response to salt stress by regulating the expression of target genes related to ion transport, protein modification, transcriptional regulation, and material synthesis and transport (Sun et al., 2020). These reports indicated the importance of epigenetic modification in the response to saline and alkali stress.

Further work is needed to expound upon the epigenetic regulatory mechanisms of plants in response to stress, especially saline-alkali stress. Additional enzymes or proteins need to be further explored, addressing how these enzymes, small RNAs and their interacting proteins work together to control DNA methylation and histone modification at specific loci that regulate stress-responsive gene expression.

\section{Perspectives}

Soil salinization has become a serious worldwide problem restricting the development of agroforestry. Research on the resistance mechanism of plants in response to saline-alkali stress is vital for selecting salt-tolerant varieties and utilizing saline land (Figure 2). Currently, studies are mainly focused primarily on salt stress and less on salt-alkali mixed stress. However, high salt and high $\mathrm{pH}$ often occur concurrently in nature, and their synergistic effect on plants is more harmful than the effect of either stress alone. Therefore, studying the resistance mechanisms of plants under mixed saline-alkali stress has more practical significance for cultivating new resistant varieties, screening new tolerance

\section{REFERENCES}

Ahanger, M. A., Alyemeni, M. N., Wijaya, L., Alamri, S. A., Alam, P., Ashraf, M., et al. (2018). Potential of exogenously sourced kinetin in protecting Solanum lycopersicum from $\mathrm{NaCl}$-induced oxidative stress through up-regulation of the antioxidant system, ascorbate-glutathione cycle and glyoxalase system. PLoS One 13:e0202175. doi: 10.1371/journal.pone.0202175

Ahanger, M. A., Aziz, U., Alsahli, A. A., Alyemeni, M. N., and Ahmad, P. (2019). Influence of exogenous salicylic acid and nitric oxide on growth, photosynthesis, and ascorbate-glutathione cycle in salt stressed Vigna angularis. Biomolecules 10:42. doi: 10.3390/biom 10010042

Ahmad, F., Singh, A., and Kamal, A. (2017). Ameliorative effect of salicylic acid in salinity stressed Pisum sativum by improving growth parameters, activating photosynthesis and enhancing antioxidant defense system. Biosci. Biotech. Res. Comm. 10, 481-489. doi: 10.21786/bbrc/10.3/22

Ahmad, P., Abass Ahanger, M., Nasser Alyemeni, M., Wijaya, L., Alam, P., and Ashraf, M. (2018). Mitigation of sodium chloride toxicity in Solanum lycopersicum L. by supplementation of jasmonic acid and nitric oxide. J. Plant Interact. 13, 64-72. doi: 10.1080/17429145.2017.1420830

Alam, P., Albalawi, T. H., Altalayan, F. H., Bakht, M. A., Ahanger, M. A., Raja, V., et al. (2019). 24-Epibrassinolide (EBR) confers tolerance against $\mathrm{NaCl}$ stress in soybean plants by up-regulating antioxidant system, ascorbate-glutathione cycle, and glyoxalase system. Biomolecules 9:640. doi: 10.3390/biom9110640 genes, and exploring new methods to improve plant tolerance to saline-alkali-stress conditions.

Saline-alkali-stress-tolerant crop breeding is a hopeful avenue for sustained agricultural development and the utilization of saline-alkali land. Many candidate genes have been cloned, and some genetically modified plants have been screened. However, the expression of these transgenes was not high, or their effect was not obvious, which may be related to the constitutive promoter used. In addition, the evaluation of tolerant transgenic plants has occurred mostly in laboratory or in greenhouse until now. It may not work well when these plants are exposed to the natural environment because of complex and variable field conditions and interactions with abiotic or biotic factors. Thus, there is still a long way to go. Nevertheless, with the development of modern biotechnology, especially molecular markers and genetagging methodologies, genome sequencing, microarray analysis and bioinformatic analysis, more tools and strategies can be applied to resolve the complex intriguing questions surrounding saline-alkali resistance.

\section{AUTHOR CONTRIBUTIONS}

SF and XL: conceptualization. XH: writing-original draft preparation. SF and XL: writing-review and editing. All authors contributed to the article and approved the submitted version.

\section{FUNDING}

This work was supported by Heilongjiang Bayi Agricultural University "Three Horizontal and Three Vertical" Project (2018 Platform Support Project-Heilongjiang Plant Growth Regulator Engineering-Technology Research Center), the "Cereals Production and Processing" Special Subject Program, and the Cereals System Project of Heilongjiang Province.

Ali, A. Y. A., Ibrahim, M. E. H., Zhou, G., Nimir, N. E. A., Jiao, X., Zhu, G., et al. (2020). Exogenous jasmonic acid and humic acid increased salinity tolerance of sorghum. Agron. J. 112, 871-884. doi: 10.1002/agj2.20072

Amirinejad, A.-A., Sayyari, M., Ghanbari, F., and Kordi, S. (2017). Salicylic acid improves salinity-alkalinity tolerance in pepper (Capsicum annuum L.). Adv. Hort. Sci. 31, 157-163. doi: 10.13128/ahs-21954

An, D., Chen, J. G., Gao, Y. Q., Li, X., Chao, Z. F., Chen, Z. R., et al. (2017). AtHKT1 drives adaptation of Arabidopsis thaliana to salinity by reducing floral sodium content. PLoS Genet. 13:e1007086. doi: 10.1371/journal.pgen.1007086

An, J. P., Yao, J. F., Xu, R. R., You, C. X., Wang, X. F., and Hao, Y. J. (2018). An apple NAC transcription factor enhances salt stress tolerance by modulating the ethylene response. Physiol. Plant. 164, 279-289. doi: 10.1111/ppl.12724

An, Y., Gao, Y., Tong, S., and Liu, B. (2021). Morphological and physiological traits related to the response and adaption of Bolboschoenus planiculmis seedlings grown under salt-alkaline stress conditions. Front. Plant Sci. 12:567782. doi: 10.3389/fpls.2021.567782

An, Y. M., Song, L. L., Liu, Y. R., Shu, Y. J., and Guo, C. H. (2016). De novo transcriptional analysis of alfalfa in response to saline-alkaline stress. Front. Plant Sci. 7:931. doi: 10.3389/fpls.2016.00931

Ardie, S. W., Liu, S., and Takano, T. (2010). Expression of the AKT1type $\mathrm{K}^{+}$channel gene from Puccinellia tenuiflora, PutAKT1, enhances salt tolerance in Arabidopsis. Plant Cell Rep. 29, 865-874. doi: 10.1007/s00299-0100872-2 
Bacha, H., Ródenas, R., López-Gómez, E., García-Legaz, M. F., Nieves-Cordones, M., Rivero, R. M., et al. (2015). High Ca2+ reverts the repression of high-affinity $\mathrm{K}^{+}$uptake produced by $\mathrm{Na}^{+}$in Solanum lycopersycum L. (var. microtom) plants. J. Plant Physiol. 180, 72-79. doi: 10.1016/j.jplph.2015.03.014

Bahmani, K., Sadat-Noori, S. A., Izadi, A., and Akbari, A. (2015). Molecular mechanisms of plant salinity tolerance: a review. Aust. J. Crop Sci. 9, 321-336. doi: 10.3316/informit.132428657147758

Blilou, I., Xu, J., Wildwater, M., Willemsen, V., Paponov, I., Friml, J., et al. (2005). The PIN auxin efflux facilitator network controls growth and patterning in Arabidopsis roots. Nature 433, 39-44. doi: 10.1038/nature03184

Bo, C., Chen, H., Luo, G., Li, W., Zhang, X., Ma, Q., et al. (2020). Maize WRKY114 gene negatively regulates salt-stress tolerance in transgenic rice. Plant Cell Rep. 39, 135-148. doi: 10.1007/s00299-019-02481-3

Borkiewicz, L., Polkowska-Kowalczyk, L., Ciesla, J., Sowinski, P., Jonczyk, M., Rymaszewski, W., et al. (2020). Expression of maize calcium-dependent protein kinase (ZmCPK11) improves salt tolerance in transgenic Arabidopsis plants by regulating sodium and potassium homeostasis and stabilizing photosystem II. Physiol. Plant. 168, 38-57. doi: 10.1111/ppl.12938

Bose, J., Xie, Y., Shen, W., and Shabala, S. (2013). Haem oxygenase modifies salinity tolerance in Arabidopsis by controlling $\mathrm{K}^{+}$retention via regulation of the plasma membrane $\mathrm{H}+$-ATPase and by altering SOS1 transcript levels in roots. J. Exp. Bot. 64, 471-481. doi: 10.1093/jxb/ers343

Camporeale, G., Oommen, A. M., Griffin, J. B., Sarath, G., and Zempleni, J. (2007). K12-biotinylated histone H4 marks heterochromatin in human lymphoblastoma cells. J. Nutr. Biochem. 18, 760-768. doi: 10.1016/j.jnutbio. 2006.12.014

Cao, B., Shu, L., and Li, A. (2019). Functional characterization of LkERF-B2 for improved salt tolerance ability in Arabidopsis thaliana. Biotech 9:263. doi: 10. 1007/s13205-019-1793-6

Cao, L., Yu, Y., Ding, X., Zhu, D., Yang, F., Liu, B., et al. (2017). The glycine soja NAC transcription factor GsNAC019 mediates the regulation of plant alkaline tolerance and ABA sensitivity. Plant Mol. Biol. 95, 253-268. doi: 10. 1007/s11103-017-0643-3

Chen, S., and Polle, A. (2010). Salinity tolerance of Populus. Plant Biol. 12, 317-333. doi: $10.1111 / j .1438-8677.2009 .00301 . \mathrm{x}$

Chen, X., Chen, G., Li, J., Hao, X., Tuerxun, Z., Chang, X., et al. (2021). A maize calcineurin B-like interacting protein kinase ZmCIPK42 confers salt stress tolerance. Physiol. Plant. 171, 161-172. doi: 10.1111/ppl.13244

Chen, Y., Li, Y., Sun, P., Chen, G., and Xin, J. (2017). Interactive effects of salt and alkali stresses on growth, physiological responses and nutrient $(\mathrm{N}, \mathrm{P})$ removal performance of Ruppia maritima. Ecol. Eng. 104, 177-183. doi: 10. 1016/j.ecoleng.2017.04.029

Cheng, Z., Zhang, X., Zhao, K., Yao, W., Li, R., Zhou, B., et al. (2019). Overexpression of ERF38 gene enhances salt and osmotic tolerance in transgenic poplar. Front. Plant Sci. 10:1375. doi: 10.3389/fpls.2019.01375

Choi, C. S., and Sano, H. (2007). Abiotic-stress induces demethylation and transcriptional activation of a gene encoding a glycerophosphodiesterase-like protein in tobacco plants. Mol. Genet. Genomics 277, 589-600. doi: 10.1007/ s00438-007-0209-1

Ciura, J., and Kruk, J. (2018). Phytohormones as targets for improving plant productivity and stress tolerance. J. Plant Physiol. 229, 32-40. doi: 10.1016/j. jplph.2018.06.013

Cobbett, C., and Goldsbrough, P. (2002). Phytochelatins and metallothioneins: roles in heavy metal detoxification and homeostasis. Annu. Rev. Plant Biol. 53, 159-182. doi: 10.1146/annurev.arplant.53.100301.135154

Colcombet, J., and Hirt, H. (2008). Arabidopsis MAPKs: a complex signalling network involved in multiple biological processes. Biochem. J. 413, 217-226. doi: 10.1042/BJ20080625

Coskun, D., Britto, D. T., Kochian, L. V., and Kronzucker, H. J. (2016). How high do ion fluxes go? A re-evaluation of the two-mechanism model of $\mathrm{K}^{+}$transport in plant roots. Plant Sci. 243, 96-104. doi: 10.1016/j.plantsci.2015.12.003

Cotsaftis, O., Plett, D., Shirley, N., Tester, M., and Hrmova, M. (2012). A twostaged model of $\mathrm{Na}^{+}$exclusion in rice explained by $3 \mathrm{D}$ modeling of HKT transporters and alternative splicing. PLoS One 7:e39865. doi: 10.1371/journal. pone. 0039865
Cutler, S. R., Rodriguez, P. L., Finkelstein, R. R., and Abrams, S. R. (2010). Abscisic acid: emergence of a core signaling network. Annu. Rev. Plant Biol. 61, 651-679. doi: 10.1146/annurev-arplant-042809-112122

Deinlein, U., Stephan, A. B., Horie, T., Luo, W., Xu, G., and Schroeder, J. I. (2014). Plant salt-tolerance mechanisms. Trends Plant Sci. 19, 371-379. doi: 10.1016/j.tplants.2014.02.001

Demidchik, V. (2014). Mechanisms and physiological roles of $\mathrm{K}^{+}$efflux from root cells. J. Plant Physiol. 171, 696-707. doi: 10.1016/j.jplph.2014.01.015

Domec, J.-C., King, J. S., Carmichael, M. J., Overby, A. T., Wortemann, R. R., Smith, K. W., et al. (2021). Root water gates and not changes in root structure provide new insights into plant physiological responses to drought, flooding and salinity. J. Exp. Bot. doi: 10.1093/jxb/erab100 Online ahead of print

Dong, W., Gao, T., Wang, Q., Chen, J., Lv, J., and Song, Y. (2020). Salinity stress induces epigenetic alterations to the promoter of MsMYB4 encoding a saltinduced MYB transcription factor. Plant Physiol. Biochem. 155, 709-715. doi: 10.1016/j.plaphy.2020.08.015

Dong, W., Liu, X., Li, D., Gao, T., and Song, Y. (2018). Transcriptional profiling reveals that a MYB transcription factor MsMYB4 contributes to the salinity stress response of alfalfa. PLoS One 13:e0204033. doi: 10.1371/journal.pone. 0204033

Drincovich, M. F., Voll, L. M., and Maurino, V. G. (2016). Editorial: on the diversity of roles of organic acids. Front. Plant Sci. 7:1592. doi: 10.3389/fpls.2016.01592

Du, B., Zhao, W., An, Y., Li, Y., Zhang, X., Song, L., et al. (2019). Overexpression of an alfalfa glutathione S-transferase gene improved the saline-alkali tolerance of transgenic tobacco. Biol. Open 8:bio043505. doi: 10.1242/bio.043505

Duan, L., Sebastian, J., and Dinneny, J. R. (2015). Salt-stress regulation of root system growth and architecture in Arabidopsis seedlings. Methods Mol. Biol. 1242, 105-122. doi: 10.1007/978-1-4939-1902-4_10

El Mahi, H., Perez-Hormaeche, J., De Luca, A., Villalta, I., Espartero, J., GamezArjona, F., et al. (2019). A critical role of sodium flux via the plasma membrane $\mathrm{Na}^{+} / \mathrm{H}+$ exchanger SOS1 in the salt tolerance of rice. Plant Physiol. 180, 1046-1065. doi: 10.1104/pp.19.00324

Falhof, J., Pedersen, J. T., Fuglsang, A. T., and Palmgren, M. (2016). Plasma membrane $\mathrm{H}+$-ATPase regulation in the center of plant physiology. Mol. Plant 9, 323-337. doi: 10.1016/j.molp.2015.11.002

Feng, Y., Zhang, W., Chen, Q., and Ma, C. (2007). Physico-chemical characteristics and microbial composition of saline-alkaline soils in Songnen Plain. Soils 39, 301-305. doi: 10.13758/j.cnki.tr.2007.02.025

Fu, J., Liu, Z., Li, Z., Wang, Y., and Yang, K. (2017). Alleviation of the effects of saline-alkaline stress on maize seedlings by regulation of active oxygen metabolism by Trichoderma asperellum. PLoS One 12:e0179617. doi: 10.1371/ journal.pone.0179617

Fujii, H., and Zhu, J.-K. (2009). Arabidopsis mutant deficient in 3 abscisic acid-activated protein kinases reveals critical roles in growth, reproduction, and stress. Proc. Natl. Acad. Sci. U.S.A. 106, 8380-8385. doi: 10.1073/pnas. 0903144106

Fujita, Y., Yoshida, T., and Yamaguchi-Shinozaki, K. (2013). Pivotal role of the AREB/ABF-SnRK2 pathway in ABRE-mediated transcription in response to osmotic stress in plants. Physiol. Plant. 147, 15-27. doi: 10.1111/j.1399-3054. 2012.01635.x

Ganguly, D. R., Crisp, P. A., Eichten, S. R., and Pogson, B. J. (2017). The Arabidopsis DNA methylome is stable under transgenerational drought stress. Plant Physiol. 175, 1893-1912. doi: 10.1104/pp.17.00744

García-Mauriño, S., Monreal, J. A., Alvarez, R., Vidal, J., and Echevarría, C. (2003). Characterization of salt stress-enhanced phosphoenolpyruvate carboxylase kinase activity in leaves of Sorghum vulgare: independence from osmotic stress, involvement of ion toxicity and significance of dark phosphorylation. Planta 216, 648-655. doi: 10.1007/s00425-002-0893-3

Gehring, M., Huh, J. H., Hsieh, T. F., Penterman, J., Choi, Y., Harada, J. J., et al. (2006). DEMETER DNA glycosylase establishes MEDEA polycomb gene selfimprinting by allele-specific demethylation. Cell 124, 495-506. doi: 10.1016/j. cell.2005.12.034

Gierth, M., and Mäser, P. (2007). Potassium transporters in plants - Involvement in $\mathrm{K}^{+}$acquisition, redistribution and homeostasis. FEBS Lett. 581, 2348-2356. doi: 10.1016/j.febslet.2007.03.035 
Grossi, C. E. M., Santin, F., Quintana, S. A., Fantino, E., and Ulloa, R. M. (2021). Calcium-dependent protein kinase 2 plays a positive role in the salt stress response in potato. Plant Cell Rep. doi: 10.1007/s00299-021-02676-77 Online ahead of print

Guo, R., Yang, Z., Li, F., Yan, C., Zhong, X., Liu, Q., et al. (2015). Comparative metabolic responses and adaptive strategies of wheat (Triticum aestivum) to salt and alkali stress. BMC Plant Biol. 15:170. doi: 10.1186/s12870-015-0546-x

Guo, S.-H., Niu, Y.-J., Zhai, H., Han, N., and Du, Y.-P. (2018). Effects of alkaline stress on organic acid metabolism in roots of grape hybrid rootstocks. Sci. Hortic. 227, 255-260. doi: 10.1016/j.scienta.2017.09.051

Guo-Hui, Y. (2012). Alkali stress induced the accumulation and secretion of organic acids in wheat. Afr. J. Agric. Res. 7, 2844-2852. doi: 10.5897/AJAR11. 2086

Han, D., Han, J., Xu, T., Li, T., Yao, C., Wang, Y., et al. (2021). Isolation and preliminary functional characterization of MxWRKY64, a new WRKY transcription factor gene from Malus xiaojinensis Cheng et Jiang. Vitro Cell. Dev. Biol. Plant 57, 202-213. doi: 10.1007/s11627-021-10171-7

Han, D., Han, J., Yang, G., Wang, S., Xu, T., and Li, W. (2020). An ERF transcription factor gene from Malus baccata (L.) Borkh, MbERF11, affects cold and salt stress tolerance in Arabidopsis. Forests 11:514.

Han, H., Wang, Q., Wei, L., Liang, Y., Dai, J., Xia, G., et al. (2018). Small RNA and degradome sequencing used to elucidate the basis of tolerance to salinity and alkalinity in wheat. BMC Plant Biol. 18:195. doi: 10.1186/s12870-018-1415-1

Hasanuzzaman, M., Bhuyan, M., Nahar, K., Hossain, M., Mahmud, J., Hossen, M., et al. (2018). Potassium: a vital regulator of plant responses and tolerance to abiotic stresses. Agronomy 8:31. doi: 10.3390/agronomy8030031

Hasegawa, P. (2013). Sodium $\left(\mathrm{Na}^{+}\right)$homeostasis and salt tolerance of plants. Environ. Exp. Bot. 92, 19-31. doi: 10.1016/j.envexpbot.2013.03.001

He, X.-J., Chen, T., and Zhu, J.-K. (2011). Regulation and function of DNA methylation in plants and animals. Cell Res. 21, 442-465. doi: $10.1038 / \mathrm{cr} .2011 .23$

He, Y., Dong, Y., Yang, X., Guo, D., Qian, X., Yan, F., et al. (2020). Functional activation of a novel R2R3-MYB protein gene, GmMYB68, confers salt-alkali resistance in soybean (Glycine max L.). Genome Biol. 63, 13-26.

He, Y., Yang, X., Xu, C., Guo, D., Niu, L., Wang, Y., et al. (2018). Overexpression of a novel transcriptional repressor GmMYB3a negatively regulates salt-alkali tolerance and stress-related genes in soybean. Biochem. Biophys. Res. Commun. 498, 586-591. doi: 10.1016/j.bbrc.2018.03.026

Hewezi, T. (2018). Editorial: epigenetic regulation of plant development and stress responses. Plant Cell Rep. 37, 1-2. doi: 10.1007/s00299-017-2233-X

Jin, S., Xu, C., Li, G., Sun, D., Li, Y., Wang, X., et al. (2017). Functional characterization of a type 2 metallothionein gene, SsMT2, from alkalinetolerant Suaeda salsa. Sci. Rep. 7:17914. doi: 10.1038/s41598-017-18263-4

Jin, X., Liu, T., Xu, J., Gao, Z., and Hu, X. (2019). Exogenous GABA enhances muskmelon tolerance to salinity-alkalinity stress by regulating redox balance and chlorophyll biosynthesis. BMC Plant Biol. 19:48. doi: 10.1186/s12870-0191660-y

Kaiwen, G., Zisong, X., Yuze, H., Qi, S., Yue, W., Yanhui, C., et al. (2020). Effects of salt concentration, $\mathrm{pH}$, and their interaction on plant growth, nutrient uptake, and photochemistry of alfalfa (Medicago sativa) leaves. Plant Signal. Behav. 15:1832373. doi: 10.1080/15592324.2020.1832373

Kaur, H., Sirhindi, G., Bhardwaj, R., Alyemeni, M. N., Siddique, K. H. M., and Ahmad, P. (2018). 28-homobrassinolide regulates antioxidant enzyme activities and gene expression in response to salt- and temperature-induced oxidative stress in Brassica juncea. Sci. Rep. 8:8735. doi: 10.1038/s41598-018-2 7032-w

Kaya, C., Higgs, D., Ashraf, M., Alyemeni, M. N., and Ahmad, P. (2020). Integrative roles of nitric oxide and hydrogen sulfide in melatonin-induced tolerance of pepper (Capsicum annuum L.) plants to iron deficiency and salt stress alone or in combination. Physiol. Plant 168, 256-277. doi: 10.1111/ppl.12976

Kayum, A., Nath, U. K., Park, J.-I., Biswas, M. K., Choi, E. K., Song, J.-Y., et al. (2018). Genome-wide identification, characterization, and expression profiling of glutathione S-transferase (GST) family in pumpkin reveals likely role in cold-stress tolerance. Genes 9:84. doi: 10.3390/genes9020084

Ketehouli, T., Zhou, Y. G., Dai, S. Y., Carther, K. F. I., Sun, D. Q., Li, Y., et al. (2021). A soybean calcineurin B-like protein-interacting protein kinase, GmPKS4, regulates plant responses to salt and alkali stresses. J. Plant Physiol. 256:153331. doi: $10.1016 /$ j.jplph.2020.153331
Khan, S. A., Li, M. Z., Wang, S. M., and Yin, H. J. (2018). Revisiting the role of plant transcription factors in the battle against abiotic stress. Int. J. Mol. Sci. 19:1634. doi: 10.3390/ijms19061634

Kobayashi, N. I., Yamaji, N., Yamamoto, H., Okubo, K., Ueno, H., Costa, A., et al. (2017). OsHKT1;5 mediates $\mathrm{Na}^{+}$exclusion in the vasculature to protect leaf blades and reproductive tissues from salt toxicity in rice. Plant J. 91, 657-670. doi: 10.1111/tpj.13595

Kobayashi, Y., Yamamoto, S., Minami, H., Kagaya, Y., and Hattori, T. (2004). Differential activation of the rice sucrose nonfermenting1-related protein kinase 2 family by hyperosmotic stress and abscisic acid. Plant Cell 16, 1163 1177. doi: 10.1105/tpc.019943

Korver, R. A., Koevoets, I. T., and Testerink, C. (2018). Out of shape during stress: a key role for auxin. Trends Plant Sci. 23, 783-793. doi: 10.1016/j.tplants.2018. 05.011

Kudla, J., Batistic, O., and Hashimoto, K. (2010). Calcium signals: the lead currency of plant information processing. Plant Cell 22, 541-563. doi: 10.1105/tpc.109. 072686

Kudla, J., Becker, D., Grill, E., Hedrich, R., Hippler, M., Kummer, U., et al. (2018). Advances and current challenges in calcium signaling. New Phytol. 218, 414-431. doi: 10.1111/nph.14966

Kulik, A., Wawer, I., Krzywiñska, E., Bucholc, M., and Dobrowolska, G. (2011). SnRK2 protein kinases-key regulators of plant response to abiotic stresses. Omics 15, 859-872. doi: 10.1089/omi.2011.0091

Kumar, M., Kesawat, M. S., Ali, A., Lee, S. C., Gill, S. S., and Kim, A. H. U. (2019). Integration of abscisic acid signaling with other signaling pathways in plant stress responses and development. Plants 8:592. doi: 10.3390/plants8120592

Kumar, V., Khare, T., Shriram, V., and Wani, S. H. (2018). Plant small RNAs: the essential epigenetic regulators of gene expression for salt-stress responses and tolerance. Plant Cell Rep. 37, 61-75. doi: 10.1007/s00299-017-2210-4

Lang, Z., Lei, M., Wang, X., Tang, K., Miki, D., Zhang, H., et al. (2015). The methylCpG-binding protein MBD7 facilitates active DNA demethylation to limit DNA hyper-methylation and transcriptional gene silencing. Mol. Cell. 57, 971-983. doi: 10.1016/j.molcel.2015.01.009

Lang, Z., Wang, Y., Tang, K., Tang, D., Datsenka, T., Cheng, J., et al. (2017). Critical roles of DNA demethylation in the activation of ripening-induced genes and inhibition of ripening-repressed genes in tomato fruit. Proc. Natl. Acad. Sci. U.S.A. 114, E4511-E4519. doi: 10.1073/pnas.1705233114

Lee, J., Eschen-Lippold, L., Lassowskat, I., Bottcher, C., and Scheel, D. (2015). Cellular reprogramming through mitogen-activated protein kinases. Front. Plant Sci. 6:940. doi: 10.3389/fpls.2015.00940

Li, H., Shi, J., Wang, Z., Zhang, W., and Yang, H. (2020). H2S pretreatment mitigates the alkaline salt stress on Malus hupehensis roots by regulating $\mathrm{Na}^{+} / \mathrm{K}^{+}$homeostasis and oxidative stress. Plant Physiol. Biochem. 156, 233241. doi: 10.1016/j.plaphy.2020.09.009

Li, J., Pu, L., Han, M., Zhu, M., Zhang, R., and Xiang, Y. (2014). Soil salinization research in China: advances and prospects. J. Geogr. Sci. 24, 943-960. doi: 10.1007/s11442-014-1130-2

Li, J., Xu, H. H., Liu, W. C., Zhang, X. W., and Lu, Y. T. (2015). Ethylene inhibits root elongation during alkaline stress through AUXIN1 and associated changes in auxin accumulation. Plant Physiol. 168, 1777-1791. doi: 10.1104/pp. 15.00523

Li, Q., Yang, A., and Zhang, W.-H. (2019). Higher endogenous bioactive gibberellins and $\alpha$-amylase activity confer greater tolerance of rice seed germination to saline-alkaline stress. Environ. Exp. Bot. 162, 357-363. doi: 10.1016/j.envexpbot.2019.03.015

Li, W., Pang, S., Lu, Z., and Jin, B. (2020). Function and mechanism of WRKY transcription factors in abiotic stress responses of plants. Plants 9:1515. doi: 10.3390/plants9111515

Li, W., Xu, G., Alli, A., and Yu, L. (2018). Plant HAK/KUP/KT K ${ }^{+}$transporters: function and regulation. Semin. Cell Dev. Biol. 74, 133-141. doi: 10.1016/j. semcdb.2017.07.009

Li, W. Y., Wang, C., Shi, H. H., Wang, B., Wang, J. X., Liu, Y. S., et al. (2020). Genome-wide analysis of ethylene-response factor family in adzuki bean and functional determination of VaERF3 under saline-alkaline stress. Plant Physiol. Biochem. 147, 215-222. doi: 10.1016/j.plaphy.2019.12.019

Li, X., Li, S., Wang, J., and Lin, J. (2020). Exogenous abscisic acid alleviates harmful effect of salt and alkali stresses on wheat seedlings. Int. J. Environ. Res. Public Health 17:3770. doi: 10.3390/ijerph17113770 
Liese, A., and Romeis, T. (2013). Biochemical regulation of in vivo function of plant calcium-dependent protein kinases (CDPK). Biochim. Biophys. Acta 1833, 1582-1589. doi: 10.1016/j.bbamcr.2012.10.024

Lin, J., Li, X., Zhang, Z., Yu, X., Gao, Z., Wang, Y., et al. (2012). Salinity-alkalinity tolerance in wheat: seed germination, early seedling growth, ion relations and solute accumulation. Afr. J. Agric. Res. 7, 467-474. doi: 10.5897/AJAR11.1417

Liu, A., Yu, Y., Duan, X., Sun, X., Duanmu, H., and Zhu, Y. (2015). GsSKP21, a Glycine soja S-phase kinase-associated protein, mediates the regulation of plant alkaline tolerance and ABA sensitivity. Plant Mol. Biol. 87, 111-124. doi: 10.1007/s11103-014-0264-z

Liu, B., Kang, C., Wang, X., and Bao, G. (2015). Physiological and morphological responses of Leymus chinensisto saline-alkali stress. Grassl. Sci. 61, 217-226. doi: $10.1111 /$ grs.12099

Liu, C. Y., Song, Y. Y., Ren, H. N., Sun, G. G., Liu, R. D., Jiang, P., et al. (2017). Cloning and expression of a Trichinella spiralis putative glutathione S-transferase and its elicited protective immunity against challenge infections. Parasit Vectors 10:448. doi: 10.1186/s13071-017-2384-1

Liu, X., Liang, W., Li, Y.-X., Li, M.-J., Ma, B.-Q., Liu, C.-H., et al. (2019). Transcriptome analysis reveals the effects of alkali stress on root system architecture and endogenous hormones in apple rootstocks. J. Integr. Agric. 18, 2264-2271. doi: 10.1016/S2095-3119(19)62706-1

Longstreth, D. J., and Nobel, P. S. (1979). Salinity effects on leaf anatomy: consequences for photosynthesis. Plant Physiol. 63, 700-703. doi: 10.1104/pp. 63.4.700

López-Bucio, J., Nieto Jacobo, M., Ramirez-Rodriguez, V. V., and Herrera-Estrella, L. (2001). Organic acid metabolism in plants: from adaptive physiology to transgenic varieties for cultivation in extreme soils. Plant Sci. 160, 1-13. doi: 10.1016/S0168-9452(00)00347-2

Lu, L., Chen, X., Zhu, L., Li, M., Zhang, J., Yang, X., et al. (2020). NtCIPK9: a calcineurin B-like protein-interacting protein kinase from the halophyte Nitraria tangutorum, enhances Arabidopsis salt tolerance. Front. Plant Sci. 11:1112. doi: $10.3389 /$ fpls.2020.01112

Lu, X., Zhang, X., Duan, H., Lian, C., Liu, C., Yin, W., et al. (2018). Three stressresponsive NAC transcription factors from Populus euphratica differentially regulate salt and drought tolerance in transgenic plants. Physiol. Plant. 162, 73-97. doi: 10.1111/ppl.12613

Luo, M., Cheng, K., Xu, Y., Yang, S., and Wu, K. (2017). Plant responses to abiotic stress regulated by histone deacetylases. Front. Plant Sci. 8:2147. doi: 10.3389/fpls.2017.02147

Luo, Q., Wei, Q., Wang, R., Zhang, Y., Zhang, F., He, Y., et al. (2017). BdCIPK31, a calcineurin B-like protein-interacting protein kinase, regulates plant response to drought and salt stress. Front. Plant Sci. 8:1184. doi: 10.3389/fpls.2017. 01184

Luo, X., Dai, Y., Zheng, C., Yang, Y., Chen, W., Wang, Q., et al. (2021). The ABI4RbohD/VTC2 regulatory module promotes reactive oxygen species (ROS) accumulation to decrease seed germination under salinity stress. New Phytol. 229, 950-962. doi: 10.1111/nph.16921

Ma, Q., Xia, Z., Cai, Z., Li, L., Cheng, Y., Liu, J., et al. (2018). GmWRKY16 enhances drought and salt tolerance through an ABA-mediated pathway in Arabidopsis thaliana. Front. Plant Sci. 9:1979. doi: 10.3389/fpls.2018.01979

Ma, S., Lv, L., Meng, C., Zhou, C., Fu, J., Shen, X., et al. (2019). Genomewide analysis of abscisic acid biosynthesis, catabolism, and signaling in Sorghum Bicolor under saline-alkali stress. Biomolecules 9:823. doi: 10.3390/ biom 9120823

Ma, Y., Xue, H., Zhang, F., Jiang, Q., Yang, S., Yue, P., et al. (2021). The miR156/SPL module regulates apple salt stress tolerance by activating MdWRKY100 expression. Plant Biotechnol. J. 19, 311-323. doi: 10.1111/pbi. 13464

Marconi, G., Pace, R., Traini, A., Raggi, L., Lutts, S., Chiusano, M., et al. (2013). Use of MSAP markers to analyse the effects of salt stress on DNA methylation in rapeseed (Brassica napus var. oleifera). PloS One 8:e75597. doi: 10.1371/journal. pone.0075597

Marques, D. N., Reis, S. P. D., and de Souza, C. R. B. (2017). Plant NAC transcription factors responsive to abiotic stresses. Plant Gene 11, 170-179. doi: 10.1016/j.plgene.2017.06.003

Matzke, M. A., and Mosher, R. A. (2014). RNA-directed DNA methylation: an epigenetic pathway of increasing complexity. Nat. Rev. Genet. 15, 394-408. doi: $10.1038 / \operatorname{nrg} 3683$
Monreal, J. A., Arias-Baldrich, C., Pérez-Montaño, F., Gandullo, J., Echevarría, C., and García-Mauriño, S. (2013). Factors involved in the rise of phosphoenolpyruvate carboxylase-kinase activity caused by salinity in sorghum leaves. Planta 237, 1401-1413. doi: 10.1007/s00425-013-1855-7

Morales-Ruiz, T., Ortega-Galisteo, A. P., Ponferrada-Marin, M. I., MartinezMacias, M. I., Ariza, R. R., and Roldan-Arjona, T. (2006). DEMETER and REPRESSOR OF SILENCING 1 encode 5-methylcytosine DNA glycosylases. Proc. Natl. Acad. Sci. U.S.A. 103, 6853-6858. doi: 10.1073/pnas.0601109103

Mousavi, S., Regni, L., Bocchini, M., Mariotti, R., Nicolò, C., Mancuso, S., et al. (2019). Physiological, epigenetic and genetic regulation in some olive cultivars under salt stress. Sci. Rep. 9:1093. doi: 10.1038/s41598-018-37496-5

Munns, R., and Tester, M. (2008). Mechanisms of salinity tolerance. Annu. Rev. Plant Biol. 59, 651-681. doi: 10.1146/annurev.arplant.59.032607.092911

Nakashima, K., and Yamaguchi-Shinozaki, K. (2013). ABA signaling in stressresponse and seed development. Plant Cell Rep. 32, 959-970. doi: 10.1007/ s00299-013-1418-1

Nathan, D., Ingvarsdottir, K., Sterner, D. E., Bylebyl, G. R., Dokmanovic, M., Dorsey, J. A., et al. (2006). Histone sumoylation is a negative regulator in Saccharomyces cerevisiae and shows dynamic interplay with positive-acting histone modifications. Genes Dev. 20, 966-976. doi: 10.1101/gad.1404206

Neina, D. (2019). The role of soil pH in plant nutrition and soil remediation. Appl. Environ. Soil Sci. 2019:5794869. doi: 10.1155/2019/5794869

Nzengue, Y., Steiman, R., Rachidi, W., Favier, A., and Guiraud, P. (2012). Oxidative stress induced by cadmium in the C6 cell line: role of copper and zinc. Biol. Trace Elem. Res. 146, 410-419. doi: 10.1007/s12011-011-9265-9

Oster, J., Shainberg, I., and Abrol, I. (1999). Reclamation of salt-affected soils. Agric. Drain. 38, 659-691. doi: 10.2134/agronmonogr38.c19

Overvoorde, P., Fukaki, H., and Beeckman, T. (2010). Auxin control of root development. Cold Spring Harb. Perspect. Biol. 2:a001537. doi: 10.1101/ cshperspect.a001537

Pál, M., Szalai, G., and Janda, T. (2015). Speculation: polyamines are important in abiotic stress signaling. Plant Sci. 237, 16-23. doi: 10.1016/j.plantsci.2015.05. 003

Pandey, G., Yadav, C. B., Sahu, P. P., Muthamilarasan, M., and Prasad, M. (2017). Salinity induced differential methylation patterns in contrasting cultivars of foxtail millet (Setaria italica L.). Plant Cell Rep. 36, 759-772. doi: 10.1007/ s00299-016-2093-9

Park, J. S., Frost, J. M., Park, K., Ohr, H., Park, G. T., Kim, S., et al. (2017). Control of DEMETER DNA demethylase gene transcription in male and female gamete companion cells in Arabidopsis thaliana. Proc. Natl. Acad. Sci. U.S.A. 114, 2078-2083. doi: 10.1073/pnas.1620592114

Peng, Y., Cai, J., Wang, W., and Su, B. (2012). Multiple inter-kingdom horizontal gene transfers in the evolution of the phosphoenolpyruvate carboxylase gene family. PLoS One 7:e51159. doi: 10.1371/journal.pone.0051159

Phukan, U. J., Jeena, G. S., Tripathi, V., and Shukla, R. K. (2017). Regulation of apetala2/ethylene response factors in plants. Front. Plant Sci. 8:150. doi: $10.3389 /$ fpls.2017.00150

Postnikova, O. A., Shao, J., and Nemchinov, L. G. (2013). Analysis of the alfalfa root transcriptome in response to salinity stress. Plant Cell Physiol. 54, 1041-1055. doi: $10.1093 / \mathrm{pcp} / \mathrm{pct} 056$

Pottosin, I., and Dobrovinskaya, O. (2014). Non-selective cation channels in plasma and vacuolar membranes and their contribution to $\mathrm{K}^{+}$transport. J. Plant Physiol. 171, 732-742. doi: 10.1016/j.jplph.2013.11.013

Pottosin, I., Olivas-Aguirre, M., Dobrovinskaya, O., Zepeda-Jazo, I., and Shabala, S. (2020). Modulation of ion transport across plant membranes by polyamines: understanding specific modes of action under stress. Front. Plant Sci. 11:616077. doi: $10.3389 /$ fpls.2020.616077

Qin, Z., Hou, F., Li, A., Dong, S., Wang, Q., and Zhang, L. (2020). Transcriptomewide identification of WRKY transcription factor and their expression profiles under salt stress in sweetpotato (Ipomoea batatas L.). Plant Biotechnol. Rep. 14, 599-611. doi: 10.1007/s11816-020-00635-4

Qiu, Y.-W., Feng, Z., Fu, M.-M., Yuan, X.-H., Luo, C.-C., Yu, Y.-B., et al. (2019). GsMAPK4, a positive regulator of soybean tolerance to salinity stress. J. Integr. Agric. 18, 372-380. doi: 10.1016/s2095-3119(18)61957-4

Qu, D., Show, P. L., and Miao, X. (2021). Transcription factor ChbZIP1 from alkaliphilic microalgae Chlorella sp. BLD enhancing alkaline tolerance in transgenic Arabidopsis thaliana. Int. J. Mol. Sci. 22:2387. doi: 10.3390/ ijms22052387 
Rehman, N., Khan, M. R., Abbas, Z., Rafique, R. S., Zaynab, M., Qasim, M., et al. (2020). Functional characterization of mitogen-activated protein kinase kinase (MAPKK) gene in halophytic Salicornia europaea against salt stress. Environ. Exp. Bot. 171:103934. doi: 10.1016/j.envexpbot.2019.103934

Richards, L. A. (1947). Diagnosis and improvement of saline and alkaline soils. Soil Sci. 64:432.

Robin, A. H. K., Matthew, C., Uddin, M. J., and Bayazid, K. N. (2016). Salinityinduced reduction in root surface area and changes in major root and shoot traits at the phytomer level in wheat. J. Exp. Bot. 67, 3719-3729. doi: 10.1093/ jxb/erw064

Rodrigues, C. R. F., Silva, E. N., Ferreira-Silva, S. L., Voigt, E. L., Viégas, R. A., and Silveira, J. A. G. (2013). High $\mathrm{K}^{+}$supply avoids $\mathrm{Na}^{+}$toxicity and improves photosynthesis by allowing favorable $\mathrm{K}^{+}: \mathrm{Na}^{+}$ratios through the inhibition of $\mathrm{Na}^{+}$uptake and transport to the shoots of Jatropha curcas plants. J. Plant Nutr. Soil Sci. 176, 157-164. doi: 10.1002/jpln.201200230

Sah, S. K., Reddy, K. R., and Li, J. (2016). Abscisic acid and abiotic stress tolerance in crop plants. Front. Plant Sci. 7:571. doi: 10.3389/fpls.2016.00571

Shabala, S. (2013). Learning from halophytes: physiological basis and strategies to improve abiotic stress tolerance in crops. Ann. Bot. 112, 1209-1221. doi: 10.1093/aob/mct205

Shah, W. H., Rasool, A., Saleem, S., Mushtaq, N. U., Tahir, I., Hakeem, K. R., et al. (2021). Understanding the integrated pathways and mechanisms of transporters, protein kinases, and transcription factors in plants under salt stress. Int. J. Genomics 2021:5578727. doi: 10.1155/2021/5578727

Shams, M., Ekinci, M., Ors, S., Turan, M., Agar, G., Kul, R., et al. (2019). Nitric oxide mitigates salt stress effects of pepper seedlings by altering nutrient uptake, enzyme activity and osmolyte accumulation. Physiol. Mol. Biol. Plants 25, 1149-1161. doi: 10.1007/s12298-019-00692-2

Shoji, T., Suzuki, K., Abe, T., Kaneko, Y., Shi, H., Zhu, J. K., et al. (2006). Salt stress affects cortical microtubule organization and helical growth in Arabidopsis. Plant Cell Physiol. 47, 1158-1168. doi: 10.1093/pcp/pcj090

Singh, A., Pandey, A., Srivastava, A. K., Tran, L.-S. P., and Pandey, G. K. (2016). Plant protein phosphatases $2 \mathrm{C}$ : from genomic diversity to functional multiplicity and importance in stress management. Crit. Rev. Biotechnol. 36, 1023-1035. doi: 10.3109/07388551.2015.1083941

Song, X., Yu, X., Hori, C., Demura, T., Ohtani, M., and Zhuge, Q. (2016). Heterologous overexpression of poplar SnRK2 genes enhanced salt stress tolerance in Arabidopsis thaliana. Front. Plant Sci. 7:612. doi: 10.3389/fpls.2016. 00612

Song, Y., Li, J., Sui, Y., Han, G., Zhang, Y., Guo, S., et al. (2020a). The sweet sorghum SbWRKY50 is negatively involved in salt response by regulating ion homeostasis. Plant Mol. Biol. 102, 603-614. doi: 10.1007/s11103-020-00966-4

Song, Y., Yang, W., Fan, H., Zhang, X., and Sui, N. (2020b). TaMYB86B encodes a R2R3-type MYB transcription factor and enhances salt tolerance in wheat. Plant Sci. 300:110624. doi: 10.1016/j.plantsci.2020.110624

Sridhar, V. V., Kapoor, A., Zhang, K., Zhu, J., Zhou, T., Hasegawa, P. M., et al. (2007). Control of DNA methylation and heterochromatic silencing by histone H2B deubiquitination. Nature 447, 735-738. doi: 10.1038/nature05 864

Su, N., Wu, Q., Chen, J., Shabala, L., Mithofer, A., Wang, H., et al. (2019). GABA operates upstream of $\mathrm{H}+$-ATPase and improves salinity tolerance in Arabidopsis by enabling cytosolic $\mathrm{K}^{+}$retention and $\mathrm{Na}^{+}$exclusion. J. Exp. Bot. 70, 6349-6361. doi: 10.1093/jxb/erz367

Su, Y., Wang, S., Zhang, F., Zheng, H., Liu, Y., Huang, T., et al. (2017). Phosphorylation of histone $\mathrm{H} 2 \mathrm{~A}$ at serine 95: a plant-specific mark involved in flowering time regulation and H2A.Z deposition. Plant Cell 29, 2197-2213. doi: 10.1105/tpc.17.00266

Sun, J., He, L., and Li, T. (2019). Response of seedling growth and physiology of Sorghum bicolor (L.) Moench to saline-alkali stress. PLoS One 14:e0220340. doi: 10.1371/journal.pone.0220340

Sun, M., Sun, X., Zhao, Y., Zhao, C., Duanmu, H., Yu, Y., et al. (2014). Ectopic expression of GsPPCK3 and SCMRP in Medicago sativa enhances plant alkaline stress tolerance and methionine content. PLoS One 9:e89578. doi: 10.1371/ journal.pone.0089578

Sun, N., Song, T., Ma, Z., Dong, L., Zhan, L., Xing, Y., et al. (2020). Overexpression of MsSiR enhances alkali tolerance in alfalfa (Medicago sativa L.) by increasing the glutathione content. Plant Physiol. Biochem. 154, 538-546. doi: 10.1016/j. plaphy.2020.07.001
Tang, J., Liu, Q., Yuan, H., Zhang, Y., and Huang, S. (2018). Molecular analysis of a novel alkaline metal salt $(\mathrm{NaCl})$-responsive WRKY transcription factor gene IlWRKY1 from the halophyte Iris lactea var. chinensis. Int. Biodeterior. Biodegradation 127, 139-145. doi: 10.1016/j.ibiod.2017.11.021

Tian, X., Wang, Z., Li, X., Lv, T., Liu, H., Wang, L., et al. (2015). Characterization and functional analysis of pyrabactin resistance-like abscisic acid receptor family in rice. Rice 8:28. doi: 10.1186/s12284-015-0061-6

Umezawa, T., Nakashima, K., Miyakawa, T., Kuromori, T., Tanokura, M., Shinozaki, K., et al. (2010). Molecular basis of the core regulatory network in ABA responses: sensing, signaling and transport. Plant Cell Physiol. 51, 1821-1839. doi: 10.1093/pcp/pcq156

Verhoeven, K. J., Jansen, J. J., Van Dijk, P. J., and Biere, A. (2010). Stress-induced DNA methylation changes and their heritability in asexual dandelions. New Phytol. 185, 1108-1118. doi: 10.1111/j.1469-8137.2009.03121.x

Viggiano, L., and de Pinto, M. C. (2017). Dynamic DNA Methylation Patterns in Stress Response. Berlin: Springer, 281-302. doi: 10.1007/978-3-319-55520-1_15

Waisel, Y. (1972). "12-Salt resistance," in Biology of Halophytes, ed. Y. Waisel (Cambridge, MA: Academic Press), 236-245. doi: 10.1016/B978-0-12-7308500.50017-9

Walker, R. R., Sedgley, M., Blesing, M. A., and Douglas, T. J. (1984). Anatomy, ultrastructure and assimilate concentrations of roots of citrus genotypes differing in ability for salt exclusion. J. Exp. Bot. 35, 1481-1494. doi: 10.1093/ jxb/35.10.1481

Wang, H., Takano, T., and Liu, S. (2018). Screening and evaluation of salinealkaline tolerant germplasm of rice (Oryza sativa L.) in soda saline-alkali soil. Agronomy 8:205. doi: 10.3390/agronomy8100205

Wang, J., Zhang, Y., Yan, X., and Guo, J. (2020). Physiological and transcriptomic analyses of yellow horn (Xanthoceras sorbifolia) provide important insights into salt and saline-alkali stress tolerance. PLoS One 15:e0244365. doi: 10.1371/ journal.pone.0244365

Wang, L., Li, Z., Lu, M., and Wang, Y. (2017). ThNAC13, a NAC transcription factor from Tamarix hispida, confers salt and osmotic stress tolerance to transgenic Tamarix and Arabidopsis. Front. Plant Sci. 8:635. doi: 10.3389/fpls. 2017.00635

Wang, L., Seki, K., Miyazaki, T., and Ishihama, Y. (2009). The causes of soil alkalinization in the Songnen Plain of Northeast China. Paddy Water Environ. 7, 259-270. doi: 10.1007/s10333-009-0166-X

Wang, Q. H., Han, W., Hou, Y. Y., Feng, L., Ye, Z. P., Gu, H. M., et al. (2018). Responses of main characters of root system to salt stress among cotton varieties with diffe-rent salt tolerance. J. Appl. Ecol. 29, 865-873. doi: 10.13287/j.10019332.201803.025

Wang, X., Ajab, Z., Liu, C., Hu, S., Liu, J., and Guan, Q. (2020). Overexpression of transcription factor SIWRKY28 improved the tolerance of Populus davidiana $\mathrm{x}$ P. bolleana to alkaline salt stress. BMC Genet. 21:103. doi: 10.1186/s12863-02000904-9

Wang, X., Geng, S., Ri, Y.-J., Cao, D., Liu, J., Shi, D., et al. (2011). Physiological responses and adaptive strategies of tomato plants to salt and alkali stresses. Sci. Hortic. 130, 248-255. doi: 10.1016/j.scienta.2011.07.006

Wang, X., Geng, S., and Shi, D. (2019). Selective restriction of root to shoot ion transport by cotyledon node zone in Kochia sieversiana may contribute to its tolerance to salt and alkali stresses. J. Plant Nutr. 42, 795-804. doi: 10.1080/ 01904167.2018.1485160

Wang, X., Wang, W., Huang, J., Peng, S., and Xiong, D. (2018). Diffusional conductance to $\mathrm{CO} 2$ is the key limitation to photosynthesis in salt-stressed leaves of rice (Oryza sativa). Physiol. Plant. 163, 45-58. doi: 10.1111/ppl.12653

Wang, X.-S., Ren, H.-L., Wei, Z.-W., Wang, Y.-W., and Ren, W.-B. (2017). Effects of neutral salt and alkali on ion distributions in the roots, shoots, and leaves of two alfalfa cultivars with differing degrees of salt tolerance. J. Integr. Agric. 16, 1800-1807. doi: 10.1016/s2095-3119(16)61522-8

Wang, Y., Jiang, L., Chen, J., Tao, L., An, Y., Cai, H., et al. (2018). Overexpression of the alfalfa WRKY11 gene enhances salt tolerance in soybean. PLoS One 13:e0192382. doi: 10.1371/journal.pone.0192382

Wang, Y., Wang, J., Zhao, X., Yang, S., Huang, L., Du, F., et al. (2020). Overexpression of the transcription factor gene OsSTAP1 increases salt tolerance in rice. Rice 13:50. doi: 10.1186/s12284-020-00405-4

Wu, G. Q., Li, Z. Q., Cao, H., and Wang, J. L. (2019). Genome-wide identification and expression analysis of the WRKY genes in sugar beet (Beta vulgaris L.) under alkaline stress. PeerJ 7:e7817. doi: 10.7717/peerj.7817 
Wu, J., Zhang, J., Li, X., Liu, J., Niu, Z., and Wang, L. (2019). An overexpression of the AP2/ERF transcription factor from Iris typhifolia in Arabidopsis thaliana confers tolerance to salt stress. Biol. Plant. 63, 776-784. doi: 10.32615/bp.2019. 082

Wu, S., Zhu, P., Jia, B., Yang, J., Shen, Y., Cai, X., et al. (2018). A glycine soja group S2 bZIP transcription factor GsbZIP67 conferred bicarbonate alkaline tolerance in Medicago sativa. BMC Plant Biol. 18:234. doi: 10.1186/s12870-018-1466-3

Xiang, D.-J., Man, L.-L., Cao, S., Liu, P., Li, Z.-G., and Wang, X.-D. (2020). Ectopic expression of an oat SnRK2 gene, AsSnRK2D, enhances dehydration and salinity tolerance in tobacco by modulating the expression of stress-related genes. Bras. J. Bot. 43, 429-446. doi: 10.1007/s40415-020-00614-7

Xiang, G., Ma, W., Gao, S., Jin, Z., Yue, Q., and Yao, Y. (2019). Transcriptomic and phosphoproteomic profiling and metabolite analyses reveal the mechanism of $\mathrm{NaHCO} 3$-induced organic acid secretion in grapevine roots. BMC Plant Biol. 19:383. doi: 10.1186/s12870-019-1990-9

Xiao, F., Li, X., He, J., Zhao, J., Wu, G., Gong, Q., et al. (2021). Protein kinase PpCIPK1 modulates plant salt tolerance in Physcomitrella patens. Plant Mol. Biol. 105, 685-696. doi: 10.1007/s11103-021-01120-4

Xin, J., Li, C., Ning, K., Qin, Y., Shang, J. X., and Sun, Y. (2021). AtPFA-DSP3, an atypical dual-specificity protein tyrosine phosphatase, affects salt stress response by modulating MPK3 and MPK6 activity. Plant Cell Environ. 44, 1534-1548. doi: 10.1111/pce.14002

Xu, J., Liu, T., Yang, S., Jin, X., Qu, F., Huang, N., et al. (2019). Polyamines are involved in GABA-regulated salinity-alkalinity stress tolerance in muskmelon. Environ. Exp. Bot. 164, 181-189. doi: 10.1016/j.envexpbot.2019.05.011

Xu, W., Jia, L., Balvaka, F., Ding, G., Shi, W., Ye, N., et al. (2012). PIN2 is required for the adaptation of Arabidopsis roots to alkaline stress by modulating proton secretion. J. Exp. Bot. 63, 6105-6114. doi: 10.1093/jxb/ers259

Yaish, M. W., Al-Lawati, A., Al-Harrasi, I., and Patankar, H. V. (2018). Genomewide DNA methylation analysis in response to salinity in the model plant caliph medic (Medicago truncatula). BMC Genomics 19:78. doi: 10.1186/s12864-0184484-5

Yan, F., Zhu, Y., Zhao, Y., Wang, Y., Li, J., Wang, Q., et al. (2020). De novo transcriptome sequencing and analysis of salt-, alkali-, and drought-responsive genes in Sophora alopecuroides. BMC Genomics 21:423. doi: 10.1186/s12864020-06823-4

Yang, C., Guo, W., and Shi, D. (2010). Physiological roles of organic acids in alkali-tolerance of the alkali-tolerant halophyte. Chloris virgata. Agron. J. 102, 1081-1089. doi: 10.2134/agronj2009.0471

Yang, T., Lu, X., Wang, Y., Xie, Y., Ma, J., Cheng, X., et al. (2020). HAK/KUP/KT family potassium transporter genes are involved in potassium deficiency and stress responses in tea plants (Camellia sinensis L.): expression and functional analysis. BMC Genomics 21:556. doi: 10.1186/s12864-020-06948-6

Yang, T. Y., Qi, Y. P., Huang, H. Y., Wu, F. L., Huang, W. T., Deng, C. L., et al. (2020). Interactive effects of $\mathrm{pH}$ and aluminum on the secretion of organic acid anions by roots and related metabolic factors in Citrus sinensis roots and leaves. Environ. Pollut. 262:114303. doi: 10.1016/j.envpol.2020.114303

Ye, T., Wang, Y., Feng, Y. Q., and Chan, Z. (2021). Physiological and metabolomic responses of bermudagrass (Cynodon dactylon) to alkali stress. Physiol. Plant. 171, 22-33. doi: 10.1111/ppl.13209

Ye, X., Wang, H., Cao, X., Jin, X., Cui, F., Bu, Y., et al. (2019). Transcriptome profiling of Puccinellia tenuiflora during seed germination under a long-term saline-alkali stress. BMC Genomics 20:589. doi: 10.1186/s12864-019-5860-5

Yip Delormel, T., and Boudsocq, M. (2019). Properties and functions of calciumdependent protein kinases and their relatives in Arabidopsis thaliana. New Phytol. 224, 585-604. doi: 10.1111/nph.16088

Yolcu, S., Ozdemir, F., Guler, A., and Bor, M. (2016). Histone acetylation influences the transcriptional activation of POX in Beta vulgaris L. and Beta maritima L. under salt stress. Plant Physiol. Biochem. 100, 37-46. doi: 10.1016/j.plaphy. 2015. 12.019

Yu, X., Du, J., Dong, Y., Lu, B., and Yang, M. (2020). Cloning and salt tolerance analysis of the PnHB7 transcription factor in Populus nigra L. Indust. Crops Prod. 158:112943. doi: 10.1016/j.indcrop.2020.112943

Yu, Y., Duan, X., Ding, X., Chen, C., Zhu, D., Yin, K., et al. (2017). A novel AP2/ERF family transcription factor from Glycine soja, GsERF71, is a DNA binding protein that positively regulates alkaline stress tolerance in Arabidopsis. Plant Mol. Biol. 94, 509-530. doi: 10.1007/s11103-017-0623-7
Yu, Y., Liu, A., Duan, X., Wang, S., Sun, X., Duanmu, H., et al. (2016). GsERF6, an ethylene-responsive factor from Glycine soja, mediates the regulation of plant bicarbonate tolerance in Arabidopsis. Planta 244, 681-698. doi: 10.1007/s00425016-2532-4

Yu, Z., Duan, X., Luo, L., Dai, S., Ding, Z., and Xia, G. (2020). How plant hormones mediate salt stress responses. Trends Plant Sci. 25, 1117-1130. doi: 10.1016/j. tplants.2020.06.008

Zhang, B., Chen, X., Lu, X., Shu, N., Wang, X., Yang, X., et al. (2018). Transcriptome analysis of Gossypium hirsutum L. reveals different mechanisms among $\mathrm{NaCl}$, $\mathrm{NaOH}$ and $\mathrm{Na} 2 \mathrm{CO} 3$ stress tolerance. Sci. Rep. 8:13527. doi: 10.1038/s41598018-31668-z

Zhang, F., Zhu, G., Du, L., Shang, X., Cheng, C., Yang, B., et al. (2016). Genetic regulation of salt stress tolerance revealed by RNA-Seq in cotton diploid wild species, Gossypium davidsonii. Sci. Rep. 6:20582. doi: 10.1038/srep20582

Zhang, H., Liu, X., Yang, X., Wu, H., Zhu, J., and Zhang, H. (2020). MiRNAmRNA integrated analysis reveals roles for miRNAs in a typical halophyte, Reaumuria soongorica, during seed germination under salt stress. Plants 9:351. doi: 10.3390/plants9030351

Zhang, H., Liu, X.-L., Zhang, R.-X., Yuan, H.-Y., Wang, M.-M., Yang, H.-Y., et al. (2017). Root damage under alkaline stress is associated with reactive oxygen species accumulation in rice (Oryza sativa L.). Front. Plant Sci. 8:1580. doi: 10.3389/fpls.2017.01580

Zhang, H., Zhang, Y., Deng, C., Deng, S., Li, N., Zhao, C., et al. (2018). The Arabidopsis Ca2+-dependent protein kinase CPK12 is involved in plant response to salt stress. Int. J. Mol. Sci. 19:4062. doi: 10.3390/ijms19124062

Zhang, L., Zhang, L., Xia, C., Zhao, G., Jia, J., and Kong, X. (2015). The novel wheat transcription factor TaNAC47 enhances multiple abiotic stress tolerances in transgenic plants. Front. Plant Sci. 6:1174. doi: 10.3389/fpls.2015.01174

Zhang, M., Kimatu, J. N., Xu, K., and Liu, B. (2010). DNA cytosine methylation in plant development. J. Genet. Genomics 37, 1-12. doi: 10.1016/S1673-8527(09) 60020-5

Zhang, P., Duo, T., Wang, F., Zhang, X., Yang, Z., and Hu, G. (2021). De novo transcriptome in roots of switchgrass (Panicum virgatum L.) reveals gene expression dynamic and act network under alkaline salt stress. BMC Genomics 22:82. doi: 10.1186/s12864-021-07368-w

Zhang, P., Wang, R., Yang, X., Ju, Q., Li, W., Lu, S., et al. (2020). The R2R3MYB transcription factor AtMYB49 modulates salt tolerance in Arabidopsis by modulating the cuticle formation and antioxidant defence. Plant Cell Environ. 43, 1925-1943. doi: 10.1111/pce.13784

Zhang, Z., Zhang, S., Zhang, Y., Wang, X., Li, D., Li, Q., et al. (2011). Arabidopsis floral initiator SKB1 confers high salt tolerance by regulating transcription and pre-mRNA splicing through altering histone H4R3 and small nuclear ribonucleoprotein LSM4 methylation. Plant Cell 23, 396-411. doi: 10.1105/tpc. 110.081356

Zhao, L., Wang, P., Hou, H., Zhang, H., Wang, Y., Yan, S., et al. (2014). Transcriptional regulation of cell cycle genes in response to abiotic stresses correlates with dynamic changes in histone modifications in maize. PLoS ONE 9:e106070. doi: 10.1371/journal.pone.0106070

Zhao, Q., Suo, J., Chen, S., Jin, Y., Ma, X., Yin, Z., et al. (2016). Na2CO3responsive mechanisms in halophyte Puccinellia tenuiflora roots revealed by physiological and proteomic analyses. Sci. Rep. 6:32717. doi: 10.1038/srep 32717

Zhao, S., Gao, H., Jia, X., Li, X., Mao, K., and Ma, F. (2021). The $\gamma$-clade HD-Zip I transcription factor MdHB-7 regulates salt tolerance in transgenic apple (Malus domestica). Plant Soil 1-14. doi: 10.1007/s11104-021-04918-9

Zhong, M., Wang, Y., Shu, S., Sun, J., and Guo, S. (2020). Ectopic expression of CsTGase enhances salt tolerance by regulating polyamine biosynthesis, antioxidant activities and $\mathrm{Na}^{+} / \mathrm{K}^{+}$homeostasis in transgenic tobacco. Plant Sci. 296:110492. doi: 10.1016/j.plantsci.2020.110492

Zhou, C., Li, F., Xie, Y., Zhu, L., Xiao, X., Ma, Z., et al. (2017). Involvement of abscisic acid in microbe-induced saline-alkaline resistance in plants. Plant Signal. Behav. 12:e1367465. doi: 10.1080/15592324.2017.1367465

Zhou, H., Lin, H., Chen, S., Becker, K., Yang, Y., Zhao, J., et al. (2014). Inhibition of the Arabidopsis salt overly sensitive pathway by 14-3-3 proteins. Plant Cell 26, 1166-1182. doi: 10.1105/tpc.113.117069

Zhou, Y., Yin, X., Wan, S., Hu, Y., Xie, Q., Li, R., et al. (2018). The Sesuvium portulacastrum plasma membrane $\mathrm{Na}^{+} / \mathrm{H}+$ antiporter SpSOS1 complemented 
the salt sensitivity of transgenic Arabidopsis sos1 mutant plants. Plant Mol. Biol. Reporter 36, 553-563. doi: 10.1007/s11105-018-1099-6

Zhu, J. K. (2009). Active DNA demethylation mediated by DNA glycosylases. Annu. Rev. Genet. 43, 143-166. doi: 10.1146/annurev-genet-102108-134205

Zhu, J. K. (2016). Abiotic stress signaling and responses in plants. Cell 167, 313-324. doi: 10.1016/j.cell.2016.08.029

Zou, Q., Xu, H., Yang, G., Yu, L., Jiang, H., Mao, Z., et al. (2021). MdbHLH106-like transcription factor enhances apple salt tolerance by upregulating MdNHX1 expression. Plant Cell Tissue Organ Cult. 145, 333-345. doi: 10.1007/s11240021-02011-8
Conflict of Interest: The authors declare that the research was conducted in the absence of any commercial or financial relationships that could be construed as a potential conflict of interest.

Copyright (c) 2021 Fang, Hou and Liang. This is an open-access article distributed under the terms of the Creative Commons Attribution License (CC BY). The use, distribution or reproduction in other forums is permitted, provided the original author(s) and the copyright owner(s) are credited and that the original publication in this journal is cited, in accordance with accepted academic practice. No use, distribution or reproduction is permitted which does not comply with these terms. 